\title{
The impact of vaccination strategies for COVID-19 in the context of
} emerging variants and increasing social mixing in Bogotá, Colombia: a

\section{mathematical modelling study}

\section{4}

${ }^{1}$ Department of Biological Sciences and Eck Institute for Global Health, University of Notre Dame, USA

${ }^{2}$ Departamento de Epidemiología Clínica y Bioestadística, Facultad de Medicina, Pontificia Universidad Javeriana, Bogotá, Colombia

${ }^{3} \mathrm{MRC}$ Centre for Global Infectious Disease Analysis, J-IDA, Imperial College London, London, UK

${ }^{4}$ Departamento de Ingeniería Eléctrica y Electrónica, Universidad Nacional de Colombia, Bogotá, Colombia

${ }^{5}$ Sub-secretaría de Salud Pública. Secretaría Distrital de Salud de Bogotá, Bogotá, Colombia ${ }^{6}$ Centro de Investigaciones en Microbiología y Biotecnología-UR (CIMBIUR), Facultad de Ciencias Naturales, Universidad del Rosario, Bogotá, Colombia.

\section{${ }^{\#}$ Correspondence: guido.espana@nd.edu, zulma.cucunuba@javeriana.edu.co}


Background: In Bogotá by August 1st, more than 27,000 COVID-19 deaths have been reported, while complete and partial vaccination coverage reached $30 \%$ and $37 \%$, respectively. Although reported cases are decreasing, the potential impact of new variants is uncertain.

31 Methods: We used an agent-based model of COVID-19 calibrated to local data. Variants and vaccination strategies were included. We estimated the impact of vaccination and modelled scenarios of early and delayed introduction of the delta variant, along with changes in mobility, social contact, and vaccine uptake over the next months.

Findings: By mid-July, vaccination may have prevented 17,800 (95\% CrI: 16,000 - 19,000) deaths in Bogotá. We found that delta could lead to a fourth wave of magnitude and timing dependent on social mixing, vaccination strategy, and delta dominance. In scenarios of early dominance of delta by mid-July, age prioritization and maintaining the interval between doses were important factors to avert deaths. However, if delta dominance occurred after midSeptember, age prioritization would be less relevant, and the magnitude of a four wave would be smaller. In all scenarios, higher social mixing increased the magnitude of the fourth wave.

42 Increasing vaccination rates from 50,000/day to 100,000/day reduced the impact of a fourth

43 wave due to delta.

\section{Interpretation:}

45 The magnitude and timing of a potential fourth wave in Bogotá caused by delta would depend on

46 social mixing and the timing of dominance. Rapidly increasing vaccination coverage with non-

47 delayed second doses could reduce the burden of a new wave.

48 Funding: NSF RAPID DEB 2027718. HERMES 50419. Medical Research Council.

49 MR/R024855/1 


\section{Research in Context}

\section{Evidence before this study}

56 The impact of vaccination strategies in the context of emerging SARS-CoV-2 variants and

57 increasing social mixing in Colombia had not been previously evaluated through mathematical

58 modelling. We searched PubMed for modelling studies using the terms "COVID-19 vaccine 59 AND model AND variant AND Colombia" or "SARS-CoV-2 AND vaccine AND model AND 60 variant AND Colombia" (From 2021/1/1 to 2021/07/31). We did not find studies addressing this 61 question. However, we found a model describing the evolution of the epidemic in the country 62 during the first year, and research on the emergence of alpha, gamma, and B.1.621 variants in 63 Colombia. We extended a previous version of our SARS-CoV-2 agent-based model for Bogotá 64 to include the potential effect of vaccination and variants. This model simulates transmission of 65 SARS-CoV-2 based on daily activity patterns of a synthetic population, representing 66 demographic and geographic characteristics of the total population of the city.

\section{Added value of this study}

68 First, our study provides a preliminary estimate of the impact of the vaccination program in 69 Bogotá in terms of the number of deaths prevented. The second major finding is the indication 70 that due to the introduction of the delta variant in the city, and based on the current knowledge of 71 its biology, there is a risk of a fourth epidemic wave, whose time of occurrence and magnitude 72 would depend mainly on three factors: when delta becomes dominant, the intensity of social 73 contact, and vaccination roll-out strategy and coverage.

\section{Implications of all the available evidence}

75 We estimate that by mid-July, vaccination may have already prevented 17,800 (95\% CrI: 16,000

76 - 19,000) deaths in Bogotá. The delta variant could become dominant and lead to a fourth wave

77 later in the year, but its timing will depend on the date of introduction, social mixing patterns,

78 and vaccination strategy. In all scenarios, higher social mixing is associated with a fourth wave

79 of considerable magnitude. If an early delta introduction occurred (dominance by mid-July), a

80 new wave may occur in August/September and in such case, age prioritization of vaccination and

81 maintaining the 21-day interval between doses of the Pfizer-BioNTech BNT162b2 are more 
82 important. However, if introduction occurred one or two months later (with dominance by mid-

83 August/September) a fourth wave would be of smaller magnitude, the age-prioritization is less

84 relevant, but maintaining the dose scheme without postponement is more important. In all

85 scenarios we found that increasing the vaccination rate from the current average of 50,000/day to

$86100,000 /$ day reduces the impact of a potential fourth wave due to the delta variant. Our study

87 indicates that given the possibility of a fourth wave in the city, it is necessary to continue

88 maintaining adherence to non-pharmacological interventions, such as the use of face masks and

89 physical distancing, to be cautious with the intensification of social activities, and that it is

90 essential to increase the current pace of vaccinations to rapidly reach high vaccination coverage

91 in the population of the city. 


\section{Introduction}

94 In Colombia, by the beginning of August 2021, 4.8 million COVID-19 cases and 122,000 deaths due to COVID-19 had been reported [1]. Bogotá contributes to close to $30 \%$ of the cases in the country, with 1.4 million reported by the first week of August [2]. The third wave of the epidemic in the country surpassed the magnitude of the previous two, and overwhelmed the capacity of the health system.

Vaccination against COVID-19 initiated in the country on February 17, 2021 with various vaccines introduced progressively (CoronaVac/Sinovac, Pfizer-BioNTech BNT162b2, Oxford/AstraZeneca (AZD1222), Janssen (J\&J) Ad26.COV2.S, and more recently Moderna (mRNA-1273). The Ministry of Health defined a prioritization strategy that started with health care workers, and then in the general population beginning with the older age groups and those with comorbidities [3]. By the beginning of August, 32\% of the total population of Colombia had received at least one dose, and about $25 \%$ had a complete scheme [3,4]. In Bogotá, 5.3 million doses had been administered, with $38 \%$ of the population having received at least one dose, and close to $30 \%$ a completed vaccination scheme [5]. Under the age-prioritization strategy, the country has started to vaccinate those above 25 years[5]. first reported on April 16, 2021, and the gamma variant (P.1) on January 29, 2021. In addition, several regions in Colombia have reported since the beginning of January the B.1.621 variant,

112 which then became dominant during the third wave of COVID-19 [6]. The delta variant

113 (B.1.617.2) was reported on July 24, 2021. This variant of concern (VOC) has overtaken as 114 dominant in various countries in Latin America such as Brazil, Mexico, and Costa Rica [7].

115 Delta has been described in the United Kingdom as 1.5 times more transmissible than alpha, with 116 increased severity, and reducing the effectiveness of vaccines [8,9]. Given the characteristics of 117 delta, it is important to quantify its potential impact if it becomes the dominant variant in Bogotá.

We used a detailed agent-based model of the epidemic in Bogotá [10,11] to explore the impact of 120 multiple circulating variants, including delta. We also studied the impact of changing social mixing patterns in the city and of different vaccination strategies. 


\section{Results}

Model calibration until third wave

126 The model was calibrated to daily reported deaths and seroprevalence data in Bogotá. Using

127 preliminary data on variants dominance in the city, observed mobility, and vaccination coverage, 128 we reproduced the daily trends of deaths, as well as the effective reproduction number and daily 129 demand of intensive care unit (ICU) beds in the city (Fig 1, Fig S4). Although the third wave has 130 been the largest in the city, and the model shows an attack rate over $80 \%$ in the city by July, our 131 simulations show that the vaccination program already had a large impact on the peak and total 132 number of deaths. Up to mid-July 2021, we estimate a total of 17,800 (95\% CrI: 16,000 - 19,000) 133 deaths averted by vaccination (Fig 1).

135 The model results suggest that the third wave of infections was caused mainly by the B.1.621

136 followed by the gamma variant (Fig S3). We estimated that the B.1.621 variant is likely to be 1.2 137 (1.2 -1.98) times more transmissible and able to evade immunity from previous infections at $37 \%$ $138(19 \%-48 \%)$, compared to the original lineage. We estimated the potential early introduction of 139 the alpha variant in Bogotá to be around November 2020, followed by the introduction of gamma 140 early in January, 2021 (Fig S2), whereas the appearance of B.1.621 may have occurred later in 141 the month [6]. Based on this framework, our baseline scenario assumed that importations from 142 the delta variant may have started in Bogotá since May 2021 (Fig S2), but in such a case, delta 143 would not become dominant before August (Fig S3). Calibrated parameters are listed in Table 144 S3. 

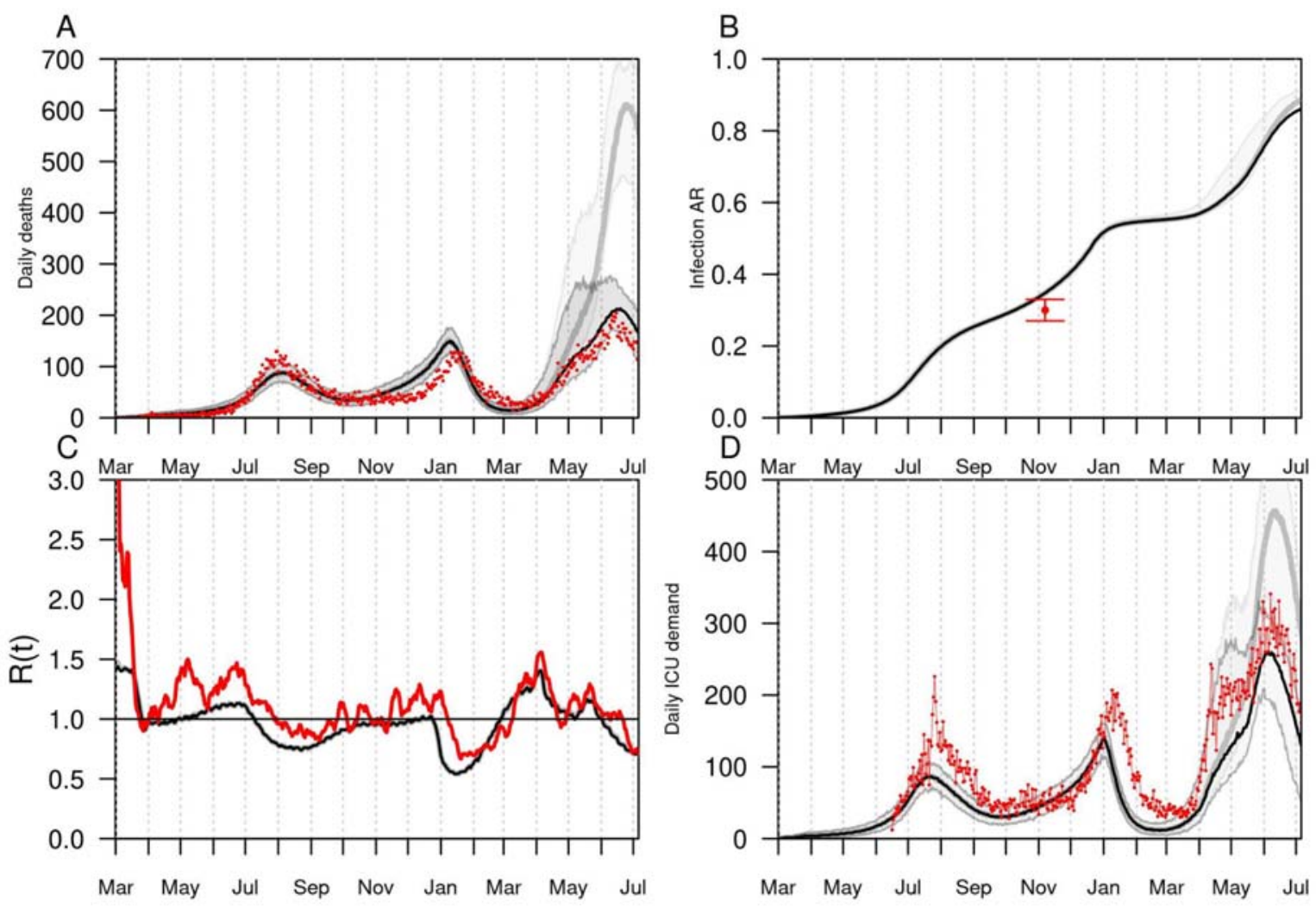

Fig 1. Model calibration and validation until third SARS-CoV-2 wave in Bogotá, Colombia. Panel A shows the daily number of deaths in the city, panel B shows the estimated infection attack rate, panel C shows the effective reproductive number, and panel D shows the daily demand for intensive care unit beds (ICU) due to COVID-19. In all panels, black lines show the calibrated model and red color the data. The gray lines show the dynamics of an alternative scenario without vaccines.

The baseline model assumes that the delta variant has already been introduced in the city but it is not yet dominant. Projections show a fourth wave of COVID-19 in the city due to the delta variant, however, its magnitude would depend on the date of introduction of delta, the social

Our model results show that the magnitude of a fourth wave of COVID-19 in Bogotá would depend on the intensity of social mixing over the coming months. The current level of social mixing assumes a moderate-high level of mobility with a moderate level of contacts, while the scenario of higher social mixing assumes an increase in the number of contacts per person, in the community overall, in addition to high levels of mobility. In all scenarios, higher social mixing increased the projected number of deaths and ICU demand in the context of a dominant delta 
variant (Fig 2). With high social mixing, an early introduction of delta would result in a peak of 189 (95\% CrI: 160-245) daily deaths, whereas a late introduction would cause a peak of 130 (95\% CrI: 116 - 180). In both scenarios of the introduction of delta, reduced social mixing resulted in a smaller peak. With moderate social mixing, an early introduction of delta would result in a peak of 104 (95\% CrI: 77-150) daily deaths, compared to 59 (95\% CrI: 47-136) daily deaths in the scenario of late introduction of delta.

Another determinant of the potential magnitude of the fourth wave is the vaccination coverage achieved by the time delta is dominant. In scenarios of an early introduction of delta (dominance

174 in August), our simulations showed that a new wave may occur in August/September, and in

175 such case, changes in the vaccination strategies would have a small effect in the dynamics of the 176 fourth wave. Nonetheless, increasing the vaccination rate to 100,000 vaccines/day could slightly 177 reduce the impact on deaths and ICU demand if age continues to be prioritized and the interval 178 between doses of the Pfizer-BioNTech BNT162b2

179 is not extended to 84 days. Extending the dose interval to 84 days resulted in an increased number of infections and deaths in this scenario, even with higher vaccination rates (Fig $3 \&$ S5, left column). In the scenario in which delta introduction occurs two months later (dominance in October), the age-prioritization for adults is less relevant but maintaining the dose scheme without postponement is more important, given that those with only one vaccine dose have lower protection against infection, particularly for delta (Table S1), which resulted in an increased number of infections and deaths at the population level (Figs S6, S7). In the scenario of dominance of delta in October, we found that increasing the vaccination rate to 100,000/day (the maximum possible according to health authorities) could have a larger impact in reducing the

188 burden of a fourth wave due to the delta variant. These findings are more pronounced if assuming that efficacy against infection is $100 \%$ of the efficacy against symptoms (Figs S8 \& S9). 

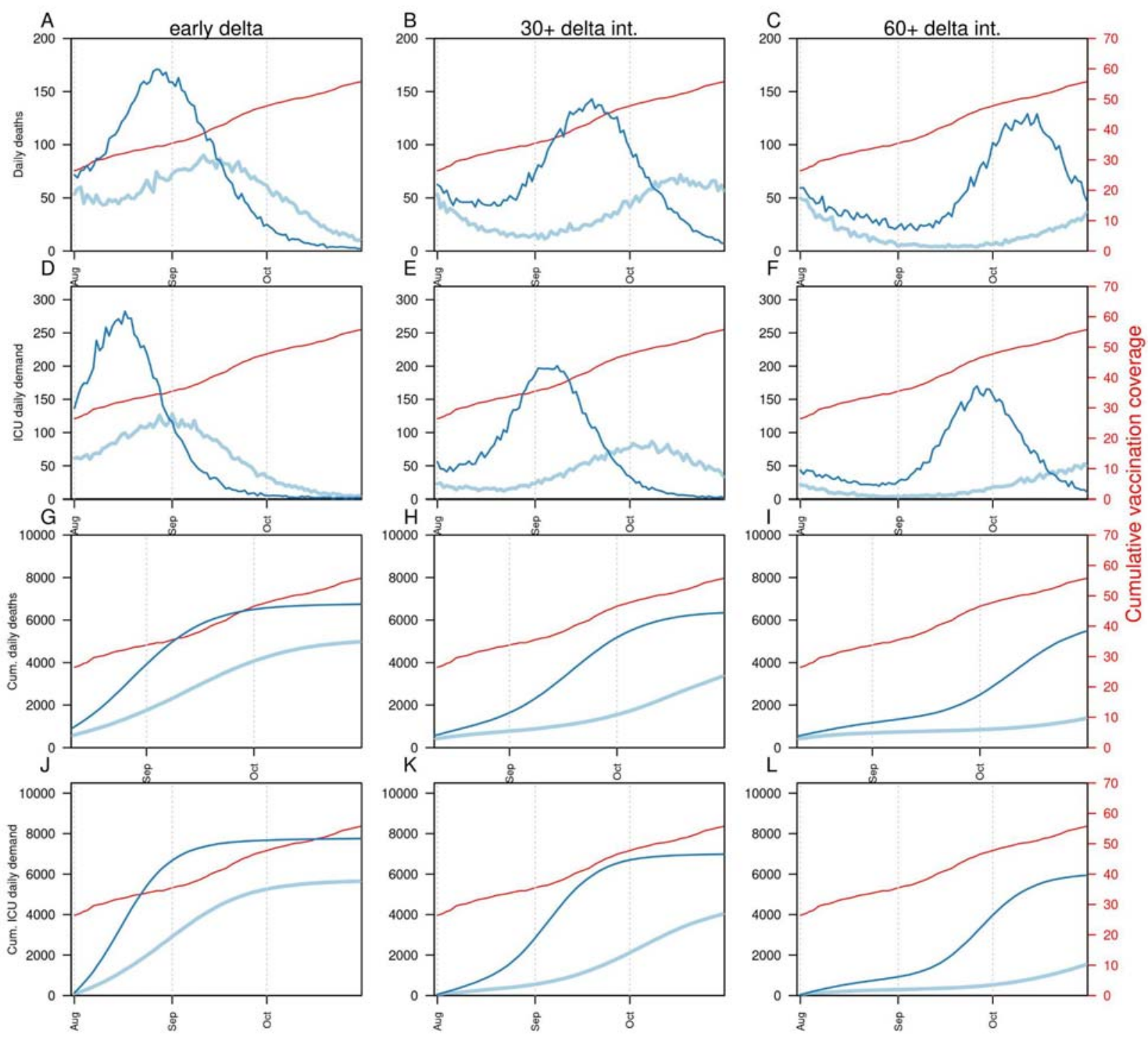

Fig 2. Projections of potential impact on deaths and ICU demand of delta variant on a fourth SARS-CoV wave in Bogotá, according to timing of delta introduction and social mixing patterns. Columns show the timing of delta introduction, defined as early (calibrated), 30+ delta (delayed 30 days), and 60+ delta (delayed 60 days). Panels A-C show the daily number of deaths, panels D-F show the daily demand for ICU beds, panels G-I show the cumulative number of deaths from August to November, and panels J-L show the cumulative number of ICU beds demanded in the city from August to November. Dark blue lines show a scenario of high mobility and high contacts, and light blue lines indicate the current estimated levels of mobility and contacts in the city. The red lines (right axis) represent the coverage of full vaccination in proportion to the total population. 

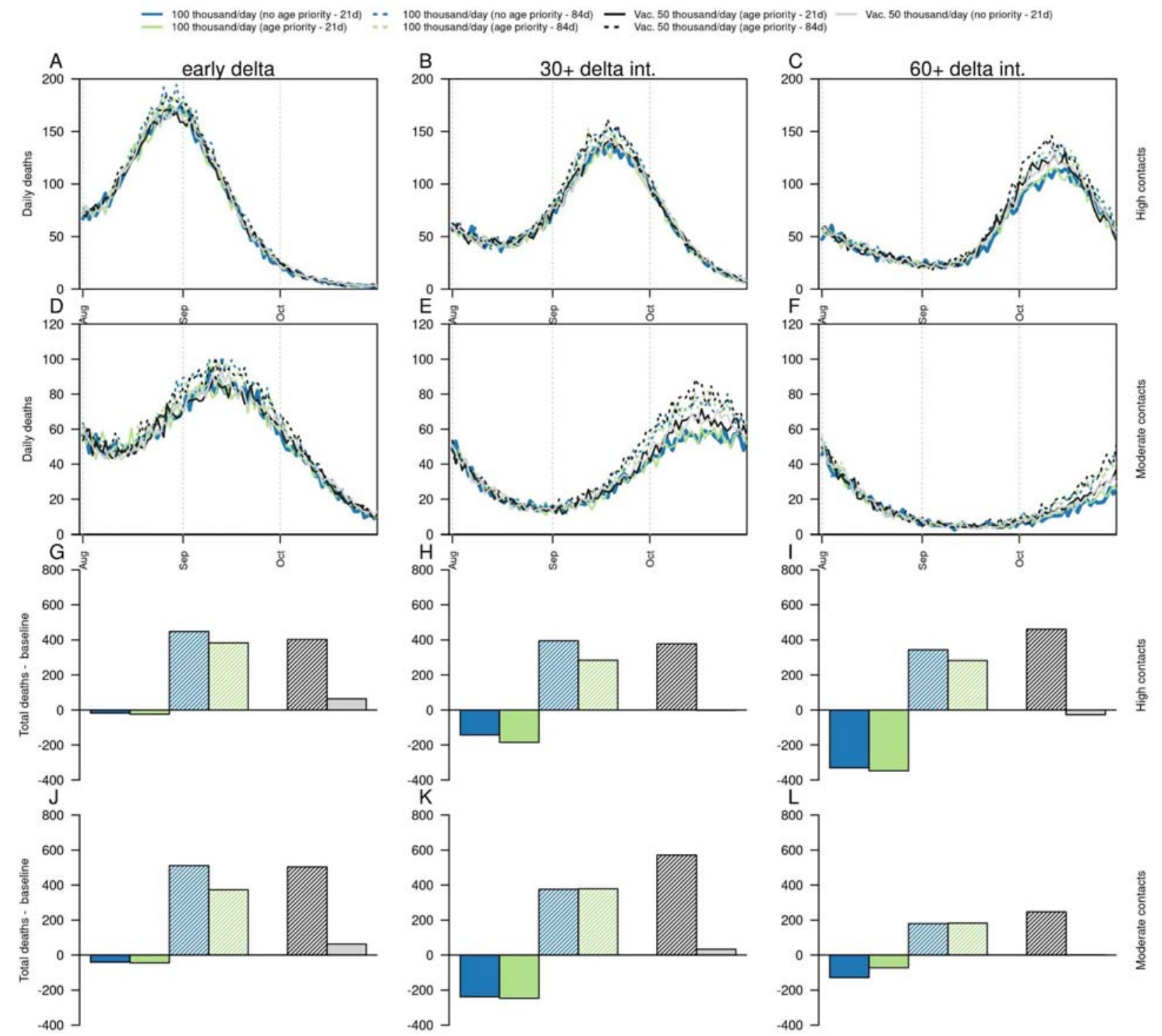

Fig 3. Projections of the potential impact on deaths of delta variant on a fourth SARS-CoV-2 wave in Bogotá, according to introduction, defined as early (calibrated), 30+ delta (delayed 30 days), and 60+ delta (delayed 60 days). Panels A-C show the daily number of deaths under a scenario of high social mixing, panels D-F show the daily number of deaths under a scenario of moderate social mixing, panels G-I show the difference in the cumulative number of deaths between alternative vaccination strategies and the baseline scenario (50 thousand vaccines/day with age prioritization and non-postponed second dose of the Pfizer vaccine) with high social mixing, and panels J-L show the difference in the cumulative number of deaths between alternative vaccination strategies and the baseline scenario (50 thousand vaccines/day with age prioritization and non-postponed second dose) with moderate social mixing. Black line shows the baseline scenario of mobility and current vaccination strategy. Dashed lines show the impact of increasing the interval between doses of the Pfizer vaccine to 84 days. Blue colors show the impact of increased vaccination rates (100,000/day) without age priority. Green colors show the impact of increased vaccination rates $(100,000 /$ day) with age priority. Gray colors show the impact of baseline vaccination rates without age priority. 


\section{Discussion}

217 We simulated the impact of the introduction of the delta variant using an agent-based model that 218 includes a detailed representation of the population of Bogotá by age, geographic location, and

219 main social activities and mobility patterns (schools, universities, workplaces, long-term care facilities, households, and neighborhoods). This model has been previously validated to COVID19 dynamics in various places $[10,11]$. We found that the increased number of cases and deaths during the third wave of COVID-19 in the city could be explained by a combination of higher mobility and social contacts, along with the presence of variants of concern or interest in particular gamma may explain the first part of the third wave, whereas B.1.621 the second part. B.1.621 may have overcome the gamma variant as dominant despite being potentially introduced at similar times. Interestingly, we found that the alpha variant was not a driver of the third wave. Our model suggests that despite an estimated high infection attack rate in the city, that there is still a risk of an additional fourth wave produced by the delta variant, whose amplitude would depend on the timing of dominance of delta, the vaccination coverage and strategy, and the level of social mixing over the next months.

We evaluated the potential impact of postponing the second dose of the Pfizer-BioNTech BNT162b2 vaccine on the potential future dynamics of COVID-19 in the city given delta dominance. We found that in our context this may not contribute to reducing the impact of a fourth wave, in contrast to previous modeling analyses that have shown benefits at the population level [12,13]. However, those studies have been evaluated for non-delta variants. Also, the benefits of second dose postponement is still under debate [14,15]. Some studies have suggested that postponing the second dose may be related with stronger and more durable immune protection [16,17]. However, even if this holds, postponement of the second dose would result in less protection against infection and disease at the individual level for those with an

242 result in a higher number of infections, and consequently deaths, at the population level. Indeed, 243 recent studies indicate that the effectiveness of the first dose of the Pfizer-BioNTech BNT162b2 244 and the Oxford/AstraZeneca (AZD1222) vaccines considerably decreases for the delta variant 245 (36\% and $30 \%$, respectively) [8]. 
247 We also evaluated the impact of different vaccination roll-out strategies. We found that even if vaccination rates are doubled, under a scenario of early introduction of delta, there might not be enough time to mitigate the impact of a fourth wave. However, if the introduction of delta is delayed or social mixing remains moderate, increasing the vaccination rates may result in a milder fourth wave. Our results suggest that in the context of a delayed presence of delta, a preferred strategy for the city is maintaining moderate levels of social mixing combined with a rapid increase in vaccination rates (even without age prioritization) and administering the second dose of the Pfizer-BioNTech BNT162b2 vaccine without postponement.

Based on data available on vaccination coverage and vaccine hesitancy for adults being estimated in population-based surveys at $12,8 \%$ [18], we assumed that about $10 \%$ of the target population remains not vaccinated, despite already being eligible. This means that for each target group defined by the vaccination campaign roll-out plan there is a remaining high-risk population that has not been vaccinated (due to hesitancy or access barriers). Although we did not model strategies to reach these populations, vaccinating these groups will have the highest impact in reducing severe disease outcomes in a future wave of COVID-19.

\section{Limitations and strengths}

265 Our model relies on data to adjust current dynamics and to project hypothetical scenarios of

266 future transmission. Currently, there is scarce data corresponding to dominance of SARS-CoV-2

267 variants in the city, which may affect our estimates of dominance of variants. Also, our

268 projections rely on our ability to project future social mixing patterns, which has proved

269 challenging. For these reasons, we have considered scenarios of moderate and high social mixing

270 levels over the coming months. Our model also relies on available data on vaccination efficacy

271 or effectiveness against multiple variants. However, for some of them, there is still considerable

272 uncertainty. These include, for instance, the effectiveness of CoronaVac/Sinovac vaccine against

273 the delta variant, and of all the vaccines against the B.1.621 variant. Moreover, our model has

274 not considered data on waning of immunity over time, but we consider parameters for loss of

275 immune protection against infection after natural infection as a fixed parameter, according to

276 literature available at the time. Also, our model assumes vaccine efficacy as a parameter but not 
many vaccine efficacy estimates against different variants are available and for that reason in

278

279

280 some cases we have used vaccine effectiveness as a proxy for vaccine efficacy. We have also used estimates of vaccine efficacy against variants developed by other authors (Table S1). Importantly, we have considered differential progression parameters for the original wild type virus and alpha and delta variants as reported in the literature. However, there is no information on those parameters for other variants. Another aspect not yet considered in our model is whether vaccination after previous infection may provide higher protection, or whether the efficacy of vaccines varies considerably according to characteristics of individuals, such as age or comorbidities [19]. This is particularly important in our context as we project a high attack rate before mass vaccination started. However, at the time of writing this manuscript, there is no information to parameterize these variations in efficacy within the model. Further work may also include estimates of the potential impact of boosters, particularly in high-risk populations.

\section{Acknowledgements}

We thank the Secretaría de Educación Distrital de Bogotá and Secretaría de Cultura for providing information and valuable insights into schools and universities distribution, size and demographics. We thank health professionals at Secretaría Distrital de Salud de Bogotá and SaluData for providing daily updated information on COVID-19 cases, deaths, ICU occupancy and demand. We thank the University of Notre Dame Center for Research Computing for computing resources. GE received funding from an NSF RAPID grant (DEB 2027718). HD received partial funding from the National University of Colombia (Universidad Nacional de Colombia (HERMES 50419)). ZMC receives funding from the Medical Research Council (MR/R024855/1). ZMC and GE are ad honorem members of the Scientific Advisory Group on epidemiological modeling at Secretaría de Salud of Bogotá. MGM holds a decision-making position at Secretaría de Salud of Bogotá. We thank Charlie Whittaker from MRC-GICA at Imperial College London for his valuable input into variant characteristics and modeling. The funding sources had no involvement in the collection, analysis, interpretation of data, the writing of the report, or in the decision to submit the paper for publication.

\section{Methods}


309 Time-varying trends of cases and deaths were obtained from public data sources. We used the

310 daily number of deaths reported in Bogotá as of mid-July 2021 [20], population based

311 seroprevalence data as of Nov, 2020 (based on anti-SARS CoV-2 IgG) [21], and available

312 prevalence data on variants over the third wave in Bogota based on 120 samples from the

313 epidemiological weeks 12 to 22 [22] to calibrate the model parameters. To represent changes in

314 mobility, we used Google Mobility Reports [23] and Grandata project [24], both freely available

315 online. Data on vaccination were obtained from datasets available online from the Ministry of

316 Health [25](Fig S1). We obtained daily ICU bed demand from the Secretary of Health of Bogotá.

317 Other data sources to create the synthetic population were obtained from official population

318 projections by age for 2021[26], IPUMS-International [27] and the Secretary of Education of

319 Bogotá.

Model

322 We extended a previous version of our SARS-CoV-2 model for Bogotá [10] to include the 323 potential effect of vaccination and variants. Our agent-based model simulates transmission of 324 SARS-CoV-2 based on daily activity patterns of a synthetic population (Fig. 4), representing 325 demographic and geographic characteristics of the total population of Bogotá. Social mixing was 326 considered in the model assuming two ways to increase contacts: mobility and average number 327 of contacts. Mobility in the model represents the proportion of people who leave their household 328 to participate in other activities, such as school or work. Community contacts are included in the 329 model as an average number of contacts that an individual has in the community, given that the 330 individual leaves the household. For instance, both mobility and community contacts may 331 increase in holidays. 

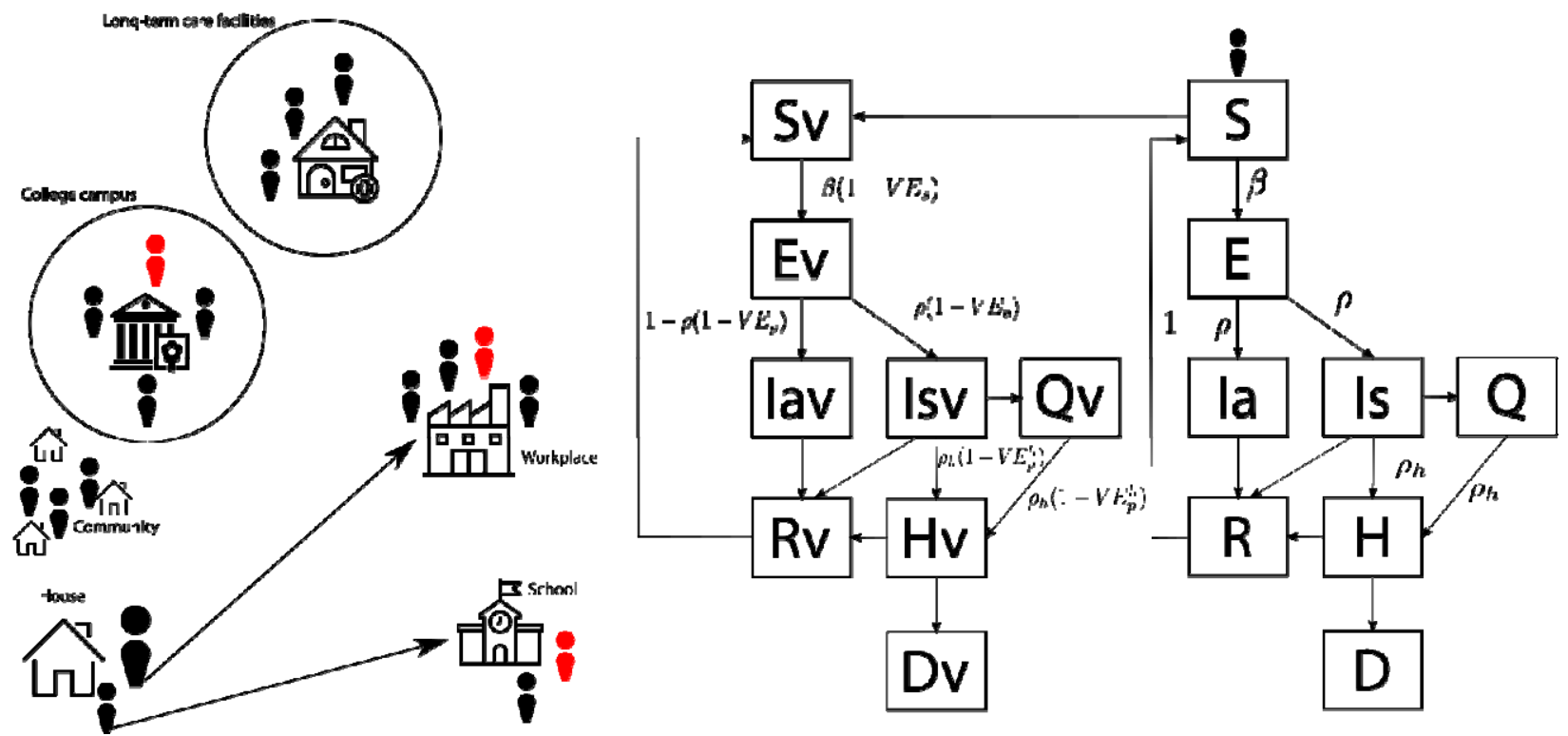

Fig 4. Model framework and individual transitions for vaccinated and unvaccinated agents.

We calibrated the model in a two-step fashion. First, we fitted parameters related to transmission of the original lineage of the virus by contrasting the model outputs to daily incidence of deaths reported from March 2020 to July 2021. Then, drawing from this calibrated distribution of parameters, we fitted parameters related to the transmissibility, immune escape (to immunity from natural infection), and introduction of the alpha, gamma, and B.1621 variants. In this step, we calibrated the model parameters to the daily incidence of deaths and the preliminary dominance data obtained from samples for epidemiologic weeks 12 to 22. Finally, the model was validated against the only available population-based seroprevalence study (conducted on November 2020 [21]) and daily ICU requests provided by the city's Secretary of Health. Parameters of the delta variant were assumed as the median value of estimates from other studies [28].

Variant's parameters and importation

348 To calibrate the parameters related to transmission and immunity escape for the different

349 variants, we used the ranges reported in the literature (Table S2). The date of introduction of 350 variants was estimated using reported cases from international travelers and the prevalence of 351 variants in their countries of origin [29], as well as the presence of the emerging B.1.621 variant 352 in the country of origin [6]. Hence, the total number of imported infections from variant ' $v$ ' can 353 be estimated as 
where $N(t)$ is the total imports detected in the city for time ' $t$ '; $\square \square(\square, \square)$ is the dominance of variant ' $v$ ' in country ' $c$ ' at time ' $t$ ' as reported at [22] as of June 30th, 2021; $\square_{\square}$ is the overall proportion of importations detected in the city from country ' $c$ '; and $\square_{\square}$ is a scaling factor estimated using daily deaths and dominance data from sequenced samples.

\section{Vaccination}

The model uses an "all-or-nothing" assumption regarding the effect of vaccination, which means that the vaccine provides no protection at all to a fraction of the vaccinated persons and perfect lifetime immunity to the rest of the vaccinated ones [30]. Other studies have reported contrasting this modelling approach with one using a "leaky" assumption about the effect of vaccination, and have not found substantial differences for their projections about the potential impact of different vaccination strategies against SARS-CoV-2 [31].

Vaccination parameters: based on the vaccination efficacy (VE) against disease $(\square \square \square \square)$, we used a function of both the efficacy against infection $\square \square_{\square}$ and against the progression from infection to disease $\square \square_{\square}$, which under a multiplicative and independent relationship can be expressed as $\square \square_{\square \square}=1-\left(1-\square \square_{\square}\right)\left(1-\square \square_{\square}\right)$ [32]. The efficacy against hospitalization could also be expressed as $\square \square_{\square \square}^{\square}=1-\left(1-\square \square_{\square}\right)\left(1-\square_{\square}\right)\left(1-\square \square_{\square}\right)$. We used

375 reported $\square \square_{\square \square}$ and $\square \square^{\square}{ }_{\square \square}$ to calculate $\square \square_{\square}$ and $\square \square^{\square}$. Given the uncertainty about the vaccine efficacy against infection, we assumed different values of $\square \square_{\square}$ (equal to $50 \%$ or $100 \%$

377 of $\left.\square \square_{\square \square}\right)$.

379 We included four vaccines currently used in Colombia, namely, Oxford/AstraZeneca 380 (AZD1222), Pfizer-BioNTech BNT162b2, CoronaVac/Sinovac, and Janssen (J\&J) Ad26.COV2.S. We used vaccine efficacy as reported from the clinical trials, except when the trial had not enough power to report efficacy (i.e. severe disease, death) or estimates were not available, in which case, results from observational studies were used. The point estimate and 
confidence intervals for the protection against symptomatic, and severe disease are listed in 385 Table S1.

We considered that the protective effect of vaccines starts after a period that can vary between 7 and 15 days after the first and the second dose according to what is reported for each vaccine (Refs in Table S1). We assumed that vaccines have some level of protection against infection. Given the uncertainty in this regard, in our main analyses we assumed that protection against infection is $50 \%$ of that reported for symptomatic disease. We also considered an alternative scenario of efficacy against infection being $100 \%$ of the efficacy against symptomatic disease. The arrival of each type of vaccine and the maximum number of vaccines delivered each day were determined by the vaccination delivery reports by the country's Ministry of Health [25], as shown in Fig S1. To project the future delivery of vaccines, we assumed constant availability with the proportion of vaccine types determined by the current one. In terms of the daily capacity of vaccine administration, we assumed that the current daily vaccination rates would remain until the target population is completely vaccinated. We also assume a probability of vaccine uptake of $90 \%$.

Of note, we have assumed that VE against hospitalization for the alpha variant with one dose is substantially different compared to the same VE for the delta variant. For this parameter we have used VE as vaccine effectiveness reported, which has not been peer-reviewed [33].

\section{Simulation scenarios}

406 We assessed the potential impact of delta variant introduction in the city by calibrating the

407 transmission model to current patterns and projecting the number of deaths and the demand for

408 ICU beds, from August to November 2021. The baseline scenario used the calibrated parameters

409 for alpha, gamma, and B.1.621. For delta, we assumed the median value of studies reported in

410 the literature [28]. The scaling factor of imports of delta was assumed to be a middle point

411 similar to values calibrated to the alpha and gamma variants.

413 We simulated a set of scenarios to calculate the impact of mobility and the timing of the 414 introduction of the delta variant. To evaluate the potential impact of mobility and contacts on the 
415 future dynamics of COVID-19 due to the delta variant, we simulated two different scenarios of

416 mobility and contacts. The baseline scenario assumed the current levels of mobility and moderate

417 contacts. We also considered a scenario of high mobility and high contacts, which assumed that

418 contacts increased to the levels observed during December 2020. We evaluated two additional

419 scenarios for the timing of the introduction of the delta variant: 30 or 60 days later than our

420 baseline estimates.

421

422 We simulated alternative scenarios of vaccination considering: the increase in the vaccination

423 capacity from 50,000 to 100,000 vaccines per day, a delivery with no age-based prioritization for

424 future administration in contrast with the current age-prioritized strategy, and the postponing of

425 the second dose of the Pfizer BioNTech's BNT162b2 mRNA vaccine (from 21 to 84 days). We

426 calculated the effect of these administration strategies on the cumulative number of deaths and

427 ICU beds required from August 1st to November 1st, 2021, and the differences with the baseline 428 scenario. 


\section{Supplementary material}

434 Table S1. Parameter values for vaccine efficacy

\begin{tabular}{|c|c|c|c|c|c|c|}
\hline Variant & \multirow{2}{*}{ Vaccine } & \multicolumn{2}{|c|}{$\begin{array}{c}\text { Efficacy against } \\
\text { Symptomatic Disease }\end{array}$} & \multicolumn{2}{|c|}{$\begin{array}{c}\text { Efficacy against } \\
\text { Severe Disease } \\
\text { (Hospitalization) }\end{array}$} & \multirow{2}{*}{ Ref } \\
\hline \multirow{6}{*}{$\begin{array}{l}\text { Pre-delta } \\
\text { variants }\end{array}$} & & One dose & Two doses & One dose & Two doses & \\
\hline & $\begin{array}{l}\text { Oxford/AstraZeneca } \\
\text { (AZD1222) }\end{array}$ & No data & $\begin{array}{l}0.78 \\
(0.68,0.85)\end{array}$ & No data & $0.9^{*}$ & $\begin{array}{l}{[34]} \\
{[35]}\end{array}$ \\
\hline & CoronaVac/Sinovac & $\begin{array}{l}0.58 \\
(0.46,0.67)\end{array}$ & $\begin{array}{l}0.51 \\
(0.36,0.62)\end{array}$ & $\begin{array}{l}0.43^{*} \\
(0.37,0.48)\end{array}$ & $\begin{array}{l}0.89^{*} \\
(0.84,0.92)\end{array}$ & [36][37] \\
\hline & $\begin{array}{l}\text { Pfizer-BioNTech } \\
\text { BNT162b2 }\end{array}$ & $\begin{array}{l}0.71 \\
(0.69,0.73)\end{array}$ & $\begin{array}{l}0.91 \\
(0.89,0.93)\end{array}$ & $0.8^{*}$ & $0.9^{*}$ & [34] [38] \\
\hline & $\begin{array}{l}\text { Moderna } \\
\text { mRNA-1273 }\end{array}$ & $\begin{array}{l}0.73 \\
(0.70,0.76)\end{array}$ & $\begin{array}{l}0.94 \\
(0.89,0.97)\end{array}$ & $0.8^{*}$ & $0.9^{*}$ & [34] [39] \\
\hline & $\begin{array}{l}\text { Janssen (J\&J) } \\
\text { Ad26.COV2.S }\end{array}$ & $\begin{array}{l}0.67 \\
(0.59,0.73)\end{array}$ & - & $\begin{array}{l}0.93 \\
(0.73,0.99)\end{array}$ & - & [40] \\
\hline \multirow{4}{*}{$\begin{array}{l}\text { Delta } \\
\text { variant }\end{array}$} & $\begin{array}{l}\text { Oxford/AstraZeneca } \\
\text { (AZD1222) }\end{array}$ & $\begin{array}{l}0.30 \\
(0.24,0.35)\end{array}$ & $\begin{array}{l}0.67 \\
(0.61,0.72)\end{array}$ & $\begin{array}{l}0.71 \\
(0.51,0.83)\end{array}$ & $\begin{array}{l}0.92 \\
(0.75-0.97)\end{array}$ & [8] [33] \\
\hline & CoronaVac/Sinovac** & $\begin{array}{l}0.46 \\
(0.37-0.54)\end{array}$ & $\begin{array}{l}0.41 \\
(0.21,0.50)\end{array}$ & $\begin{array}{l}0.43 \\
(0.37,0.48)\end{array}$ & $\begin{array}{l}0.89 \\
(0.84,0.92)\end{array}$ & $\begin{array}{l}\text { Inferred } \\
\text { from [41] } \\
\text { and [42] }\end{array}$ \\
\hline & $\begin{array}{l}\text { Pfizer-BioNTech } \\
\text { BNT162b2 }\end{array}$ & $\begin{array}{l}0.36 \\
(0.23-0.46)\end{array}$ & $\begin{array}{l}0.88 \\
(0.85-0.90)\end{array}$ & $\begin{array}{l}0.94 \\
(0.46-0.99)\end{array}$ & $\begin{array}{l}0.96 \\
(0.86-0.99)\end{array}$ & [8] [33] \\
\hline & $\begin{array}{l}\text { Moderna } \\
\text { mRNA-1273 }\end{array}$ & $\begin{array}{l}0.36 \\
(0.23-0.46)\end{array}$ & $\begin{array}{l}0.88 \\
(0.85-0.90)\end{array}$ & $\begin{array}{l}0.94 \\
(0.46-0.99)\end{array}$ & $\begin{array}{l}0.96 \\
(086 .-0.99)\end{array}$ & $\begin{array}{l}\text { Assumed } \\
\text { from [8] }\end{array}$ \\
\hline
\end{tabular}


medRxiv preprint doi: https://doi.org/10.1101/2021.08.06.21261734; this version posted September 7, 2021. The copyright holder for this preprint (which was not certified by peer review) is the author/funder, who has granted medRxiv a license to display the preprint in perpetuity.

It is made available under a CC-BY 4.0 International license.

\section{5}

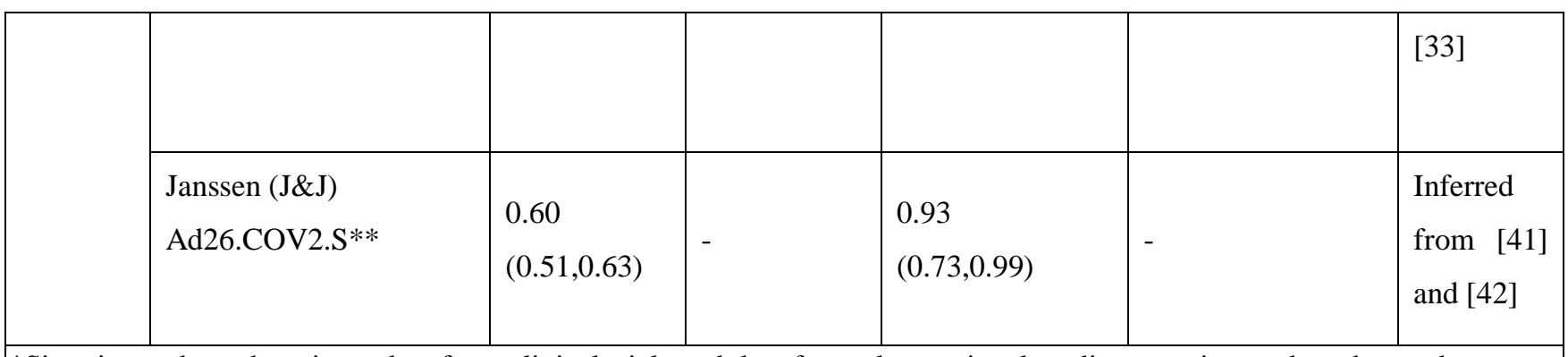

*Situations where there is no data from clinical trials and data from observational studies or estimates by other authors were used.

** Situations where either efficacy or effectiveness data are not available and values were inferred based on model by [41] and [42] 
medRxiv preprint doi: https://doi.org/10.1101/2021.08.06.21261734; this version posted September 7, 2021. The copyright holder for this preprint (which was not certified by peer review) is the author/funder, who has granted medRxiv a license to display the preprint in perpetuity.

It is made available under a CC-BY 4.0 International license.

439

440 Table S2. Parameter bounds for characteristics of variants included in the calibration.

441

\begin{tabular}{|l|l|l|l|l|}
\hline Variant & Transmission & Immune Escape & $\begin{array}{l}\text { Date first } \\
\text { reported in } \\
\text { Colombia }\end{array}$ & Source \\
\hline Alpha (B.1.1.7) & 1.5 & $0.00-0.05$ & $2021-03-10$ & {$[43]$} \\
\hline Gamma (P.1) & $1.7-2.4$ & $0.21-0.46$ & $2021-03-24$ & {$[44]$} \\
\hline Delta (B.1.617.2) & $2.10-2.46$ & $0.10-0.55$ & $2021-07-24$ & {$[28]$} \\
\hline B.1621 & $1.0-2.0$ & $0.0-0.5$ & $2021-03-14$ & $\begin{array}{l}\text { Used as range for } \\
\text { estimation within the } \\
\text { model }\end{array}$ \\
\hline
\end{tabular}

442

443

444 
medRxiv preprint doi: https://doi.org/10.1101/2021.08.06.21261734; this version posted September 7, 2021. The copyright holder for this preprint (which was not certified by peer review) is the author/funder, who has granted medRxiv a license to display the preprint in perpetuity.

It is made available under a CC-BY 4.0 International license .

Table S3. Calibrated parameters.

\begin{tabular}{|c|c|c|}
\hline Parameter & Value & Source \\
\hline $\begin{array}{l}\text { Transmissibility of original wild } \\
\text { type viruses }\end{array}$ & 0.37 & Calibrated \\
\hline $\begin{array}{l}\text { Alpha transmissibility compared to } \\
\text { original wild type viruses }\end{array}$ & 1.5 & [43] \\
\hline $\begin{array}{l}\text { Gamma transmissibility compared } \\
\text { to original wild type viruses }\end{array}$ & 2.0 (95\% CrI: $1.1-2.2)$ & Calibrated based on [44] \\
\hline $\begin{array}{l}\text { B.1.621 transmissibility compared } \\
\text { to original wild type viruses }\end{array}$ & 1.23 & Calibrated \\
\hline $\begin{array}{l}\text { Delta transmissibility compared to } \\
\text { original wild type viruses }\end{array}$ & 2.1 & Assumed based on [28] \\
\hline $\begin{array}{l}\text { Alpha escape to immunity from } \\
\text { natural infection }\end{array}$ & 0.089 (95\% CrI: 0.086 - 0.094) & Calibrated based on [43] \\
\hline $\begin{array}{l}\text { Gamma escape to immunity from } \\
\text { natural infection }\end{array}$ & 0.27 (95\% CrI: $0.26-0.29)$ & Calibrated based on [44] \\
\hline $\begin{array}{l}\text { B.1.621 escape to immunity from } \\
\text { natural infection }\end{array}$ & 0.45 ( $95 \%$ CrI: $0.19-0.45)$ & Calibrated \\
\hline $\begin{array}{l}\text { Delta escape to immunity from } \\
\text { natural infection }\end{array}$ & 0.3 & Assumed based on [28] \\
\hline Alpha importations scaling factor & 5.9 (95\% CrI: 2.9-8) & Calibrated \\
\hline Gamma importations scaling factor & 6 (95\% CrI: 5.9 - 9.35) & Calibrated \\
\hline B.1.621 Bogotá importation day & $\begin{array}{l}\text { 2021/01/24 (2021/01/04 - } \\
2021 / 02 / 17)\end{array}$ & Calibrated \\
\hline Delta importations scaling factor & 5 & Assumed \\
\hline Facemask adherence & 0.71 & Calibrated \\
\hline
\end{tabular}


A
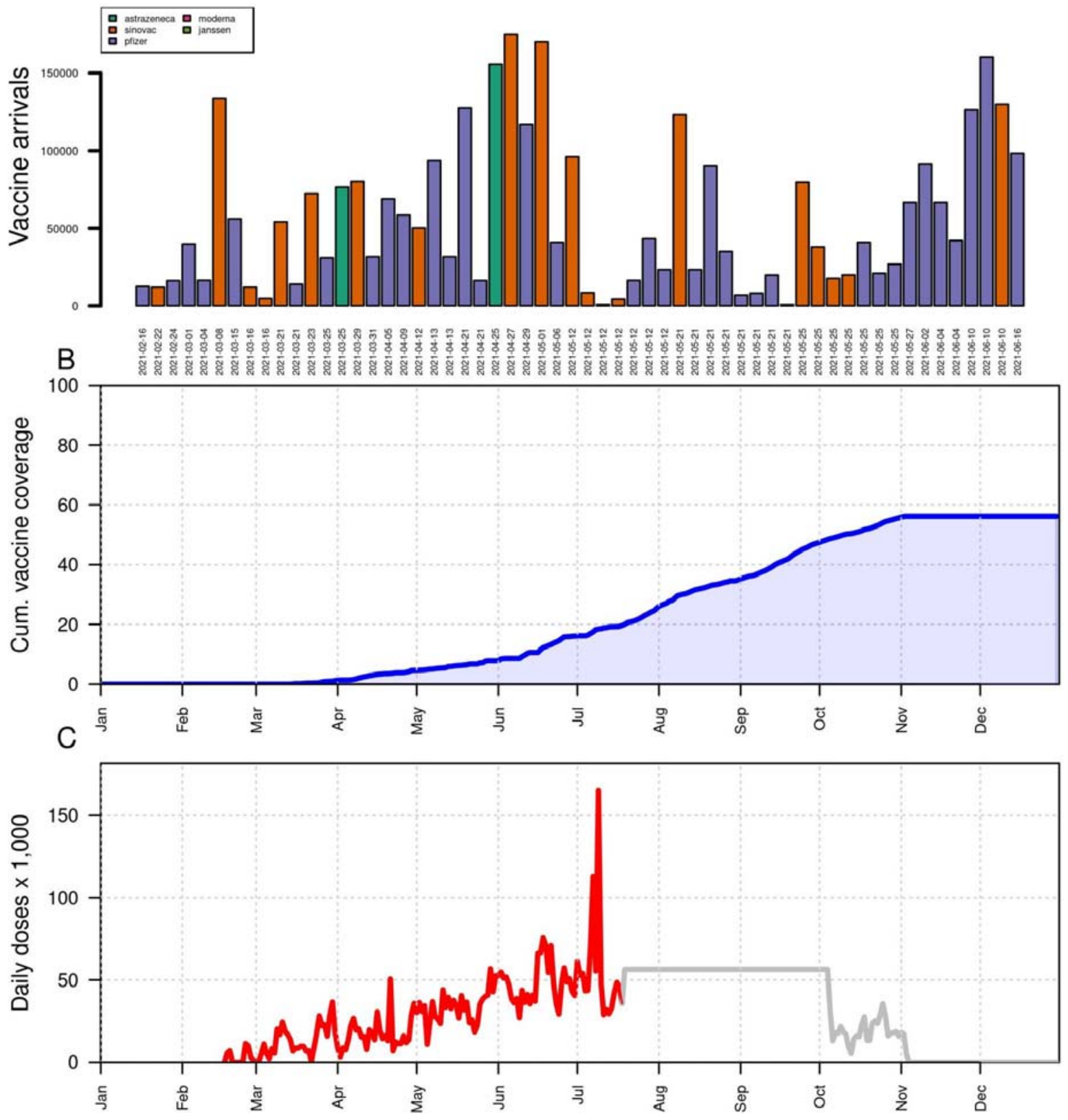

Fig S1. Vaccine stock and coverage in Bogotá. Panel A shows the arrival of vaccines by date and type of vaccine, panel B shows the projected coverage of full vaccination (fully vaccinated individuals divided by the total population of the city), and 
A
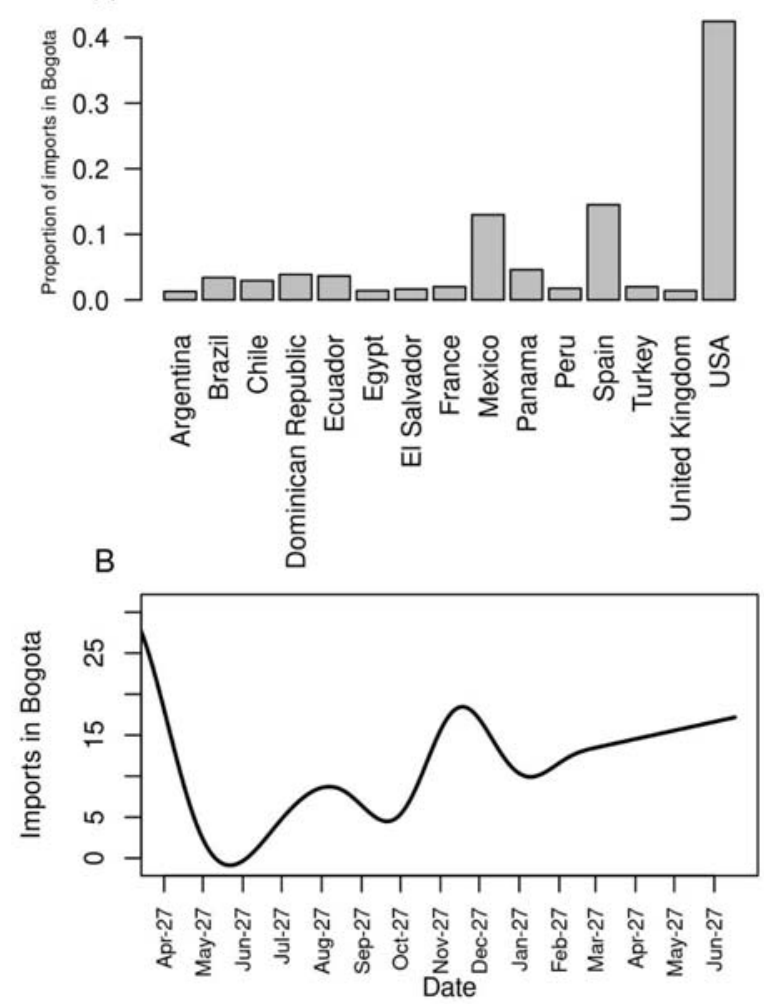

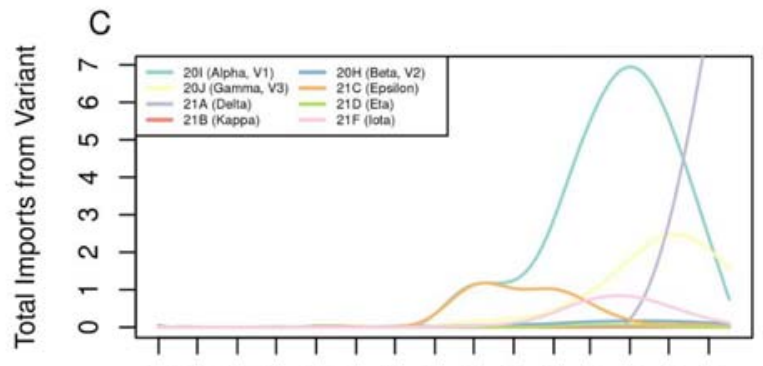

ติ่
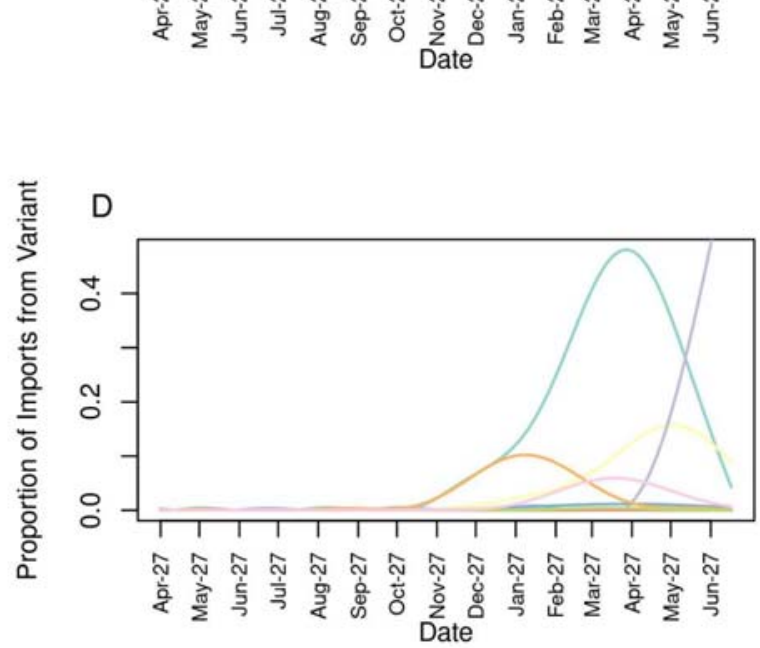

Fig S2. Importation of SARS-CoV-2 infections to Bogotá by variants and country of origin. Panel A shows the proportion of countries of origin from detected importations in the city of Bogotá, panel B shows a smoothed line of the trend of imports in the city, panel $\mathrm{C}$ shows the baseline estimated imports for each variant in the city, and panel D shows the proportion of the imports 
A

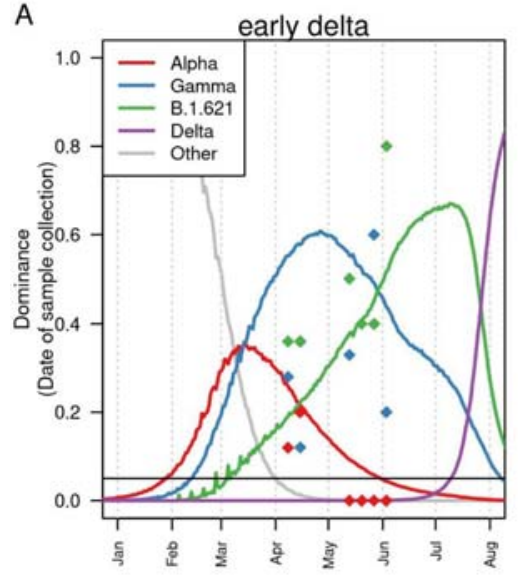

B

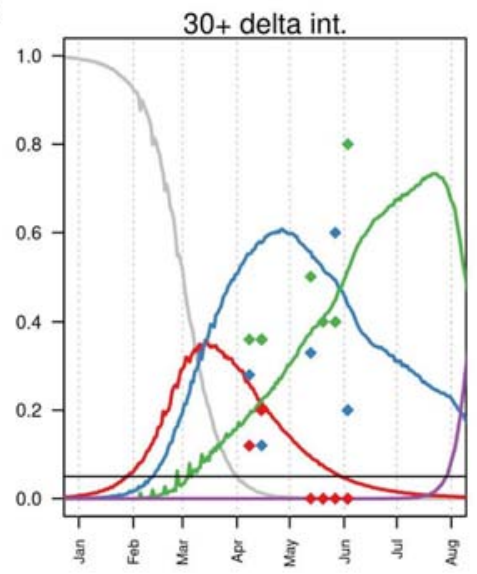

C

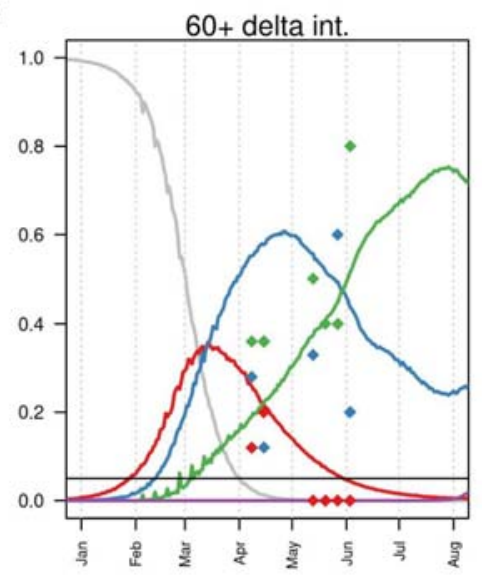

Fig S3. Model fit to dominance of variants. Panel A shows the dominance of different variants in the city for the scenario of early introduction of delta, panel B shows the dominance of variants for the scenario of delta 30+ (30 days delayed), and panel C shows the dominance of variants for the scenario of delta 60+(60 days delayed). Each line shows the dominance of each variant as estimated by the model. Diamonds show the data on dominance from these variants. Date of sample collection calculated as 7 days after infection. 

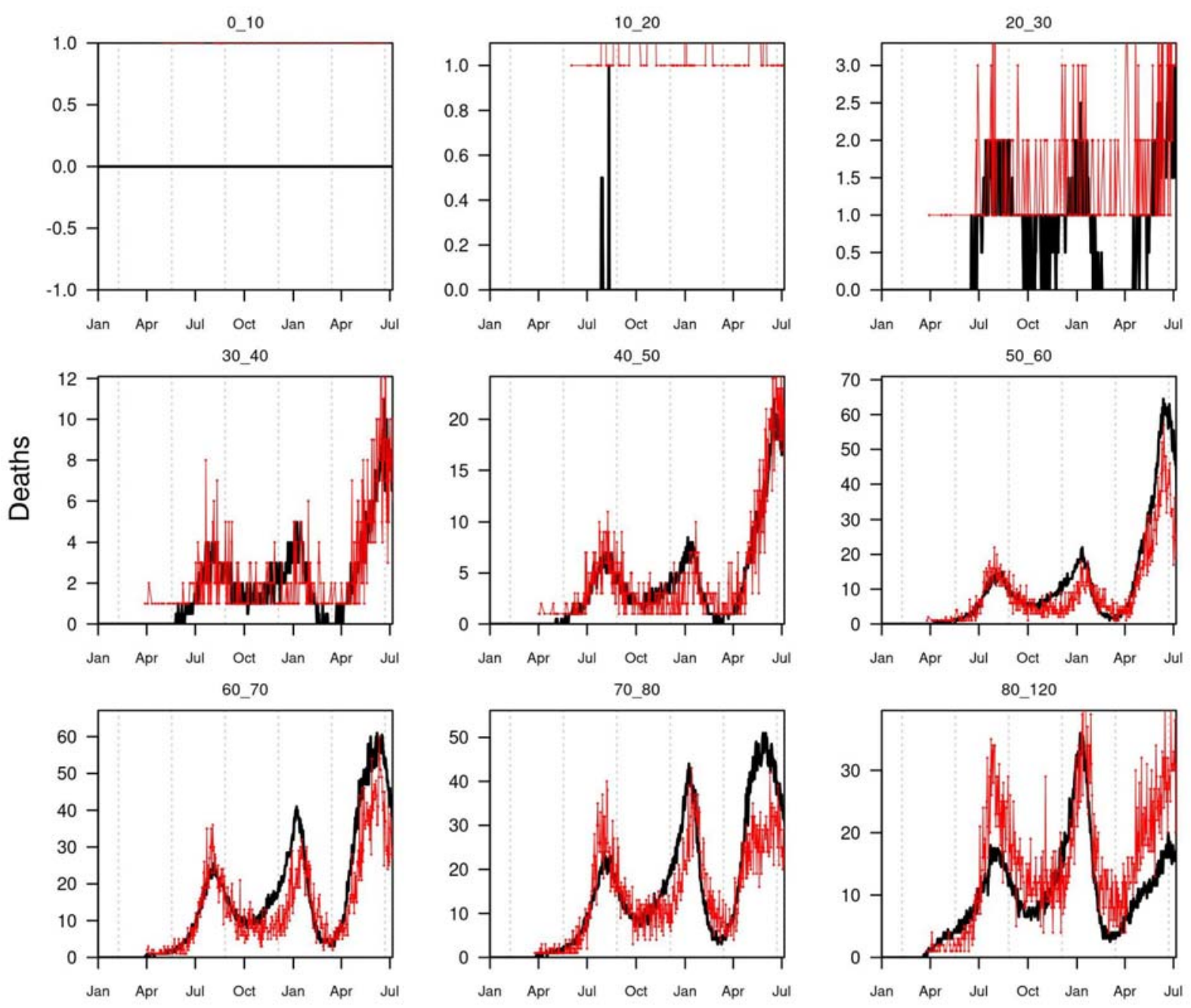

Fig S4. Model fit to age-specific deaths. Black lines show the model daily number of deaths, and red dots and lines show the reported daily deaths for each age group. 


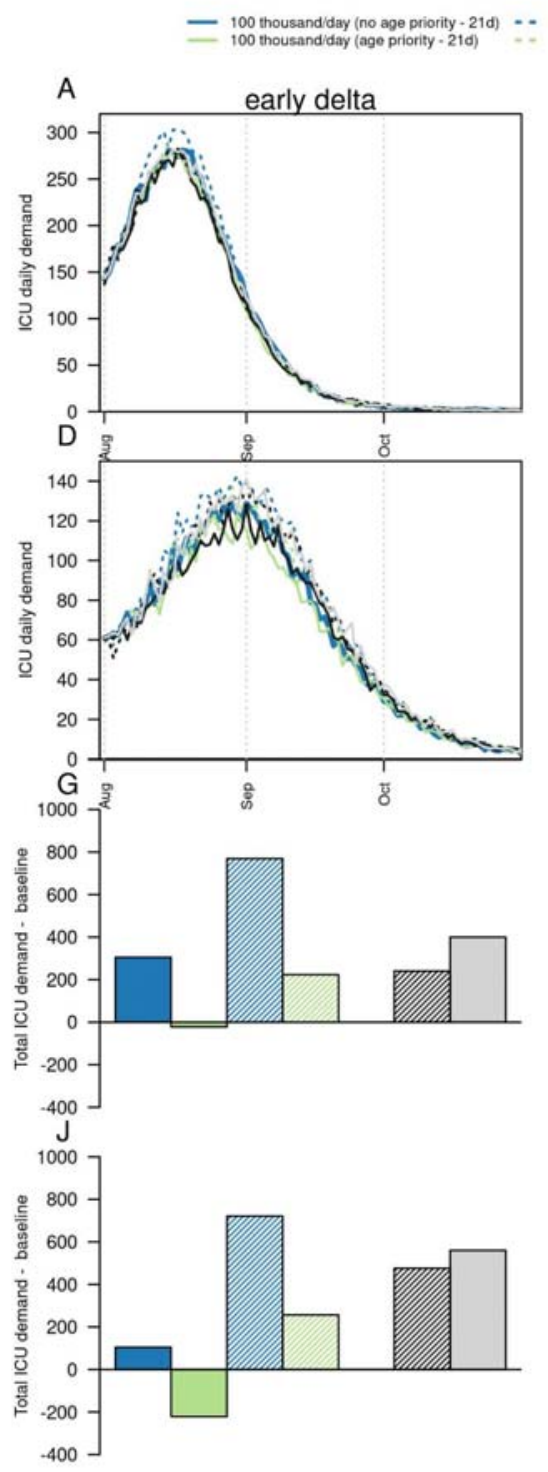
100 thousandiday (no age priority - 84d) - Vac. 50 thousandiday (age priority $-21 d$ ) - Vac. 50 thousandiday (no priority - 21d)
100 thousand day (age priority - 84d)
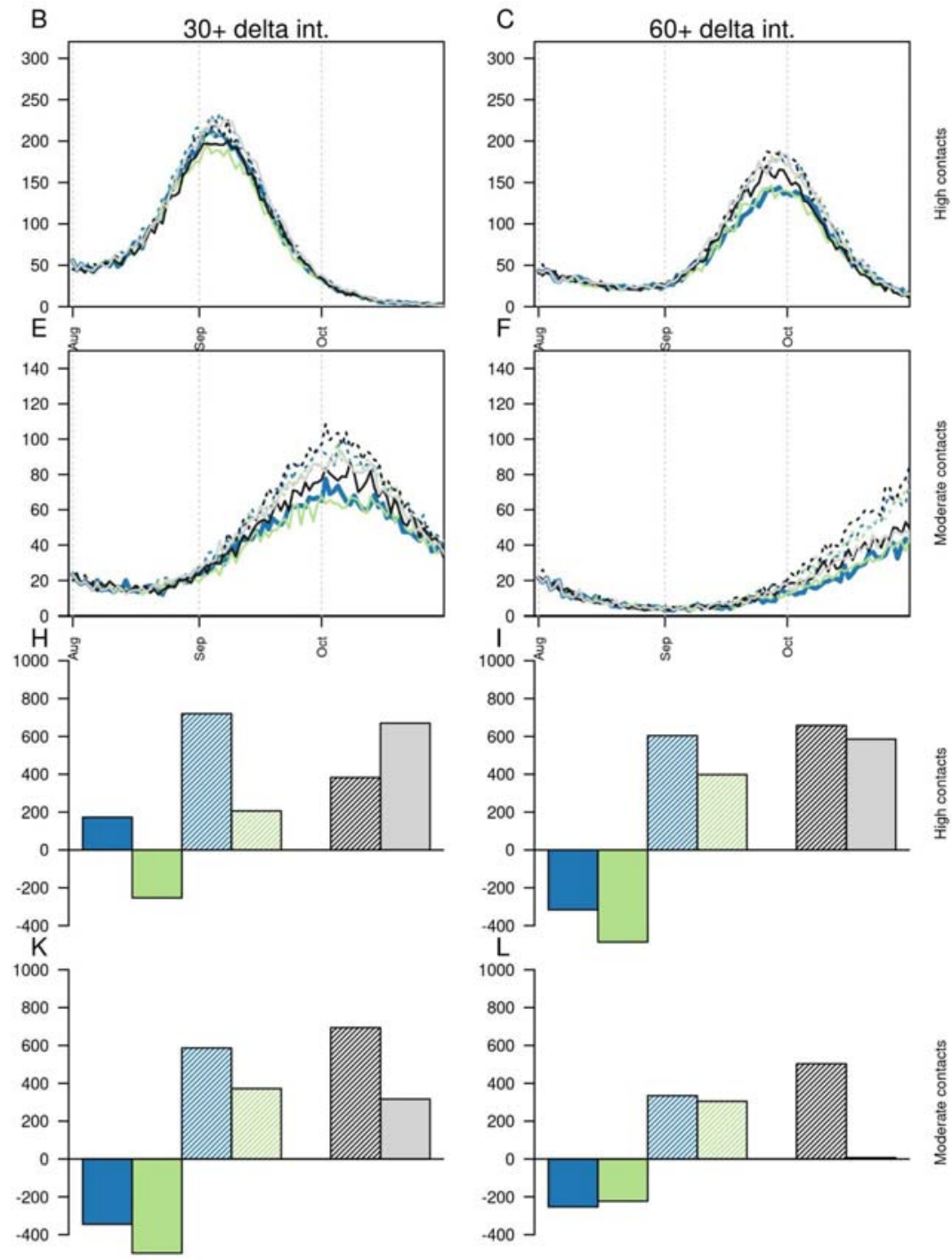

Fig S5. Projections of potential impact on ICU beds demand of delta variant on a fourth SARS-CoV-2 wave in Bogotá, according to timing of delta introduction, level of social mixing, and vaccination strategies. Columns show the timing of delta introduction, defined as early (calibrated), 30+ delta (delayed 30 days), and 60+ delta (delayed 60 days). Panels A-C show the daily number of ICU beds demanded under a scenario of high social mixing, panels D-F show the daily number of ICU beds demanded under a scenario of moderate social mixing, panels G-I show the difference in the cumulative number of ICU beds demanded between alternative vaccination strategies and the baseline scenario (50 thousand vaccines/day with age prioritization and non-postponed second dose of the Pfizer vaccine) with high social mixing, and panels J-L show the difference in the cumulative number of ICU beds between alternative vaccination strategies and the baseline scenario (50 thousand vaccines/day with age prioritization and non-postponed second dose) with moderate social mixing. Black line shows the baseline scenario of mobility and current vaccination strategy. Dashed lines show the impact of increasing the interval between doses to 84 days for the Pfizer vaccine. Blue colors show the impact of increased vaccination rates (100,000/day) without age priority. Green colors 

vaccination rates without age priority.
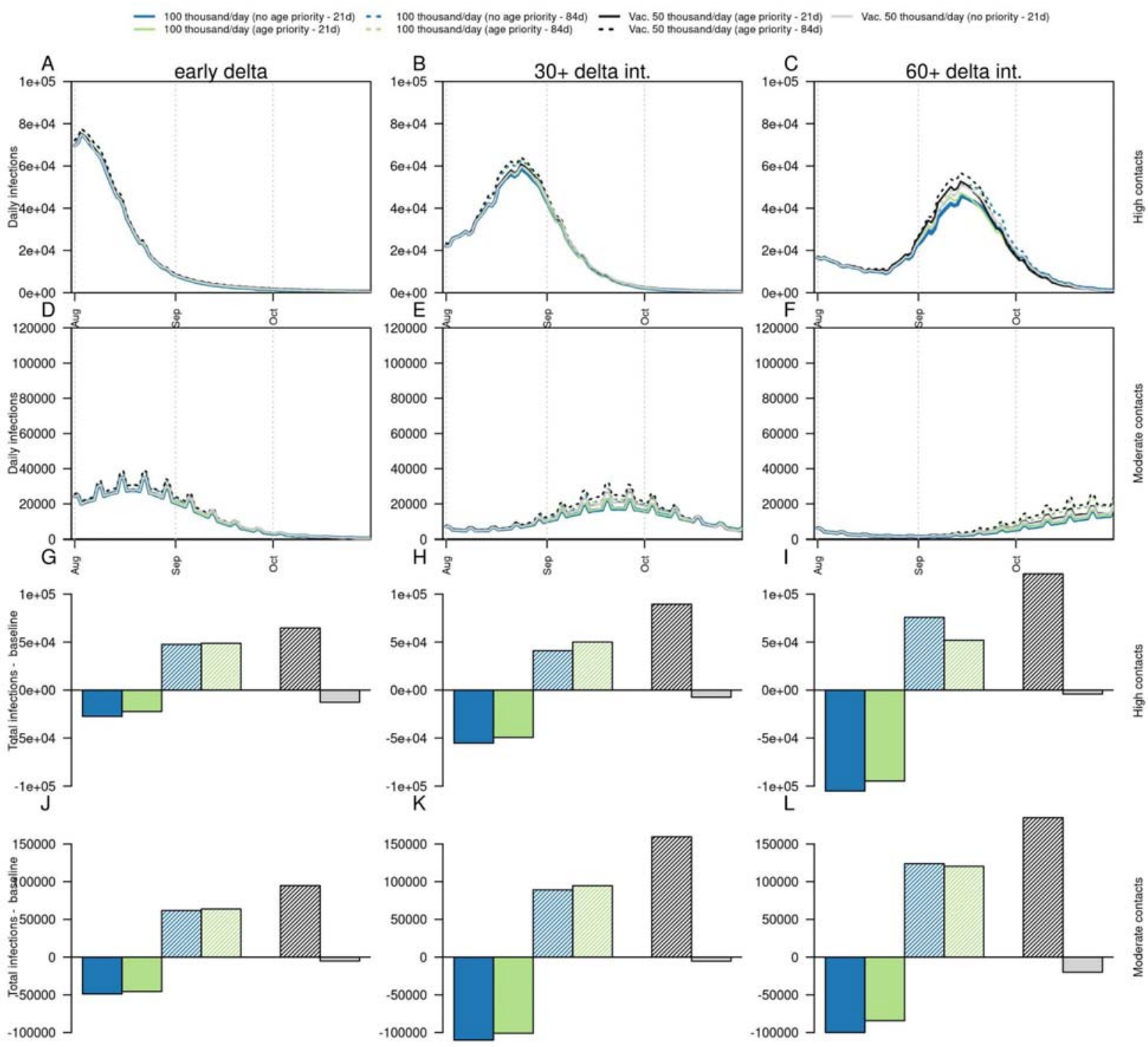

Fig S6. Projections of potential impact on infections of delta variant on a fourth SARS-CoV-2 wave in Bogotá, according against infection (50\% of VE against symptomatic disease). Columns show the timing of delta introduction, defined as early (calibrated), 30+ delta (delayed 30 days), and 60+ delta (delayed 60 days). Panels A-C show the daily number of infections under a scenario of high social mixing, panels D-F show the daily number of infections under a scenario of moderate social mixing, panels G-I show the difference in the cumulative number of infections between alternative vaccination strategies and the baseline scenario (50 thousand vaccines/day with age prioritization and non-postponed second dose of the Pfizer vaccine) with high social mixing, and panels J-L show the difference in the cumulative number of infections between alternative vaccination strategies and the baseline scenario (50 thousand vaccines/day with age prioritization and non-postponed second dose of the 
Dashed lines show the impact of increasing the interval between doses to 84 days for the Pfizer vaccine. Blue colors show the impact of increased vaccination rates (100,000/day) without age priority. Green colors show the impact of increased vaccination rates (100,000/day) with age priority. Gray colors show the impact of baseline vaccination rates without age priority.

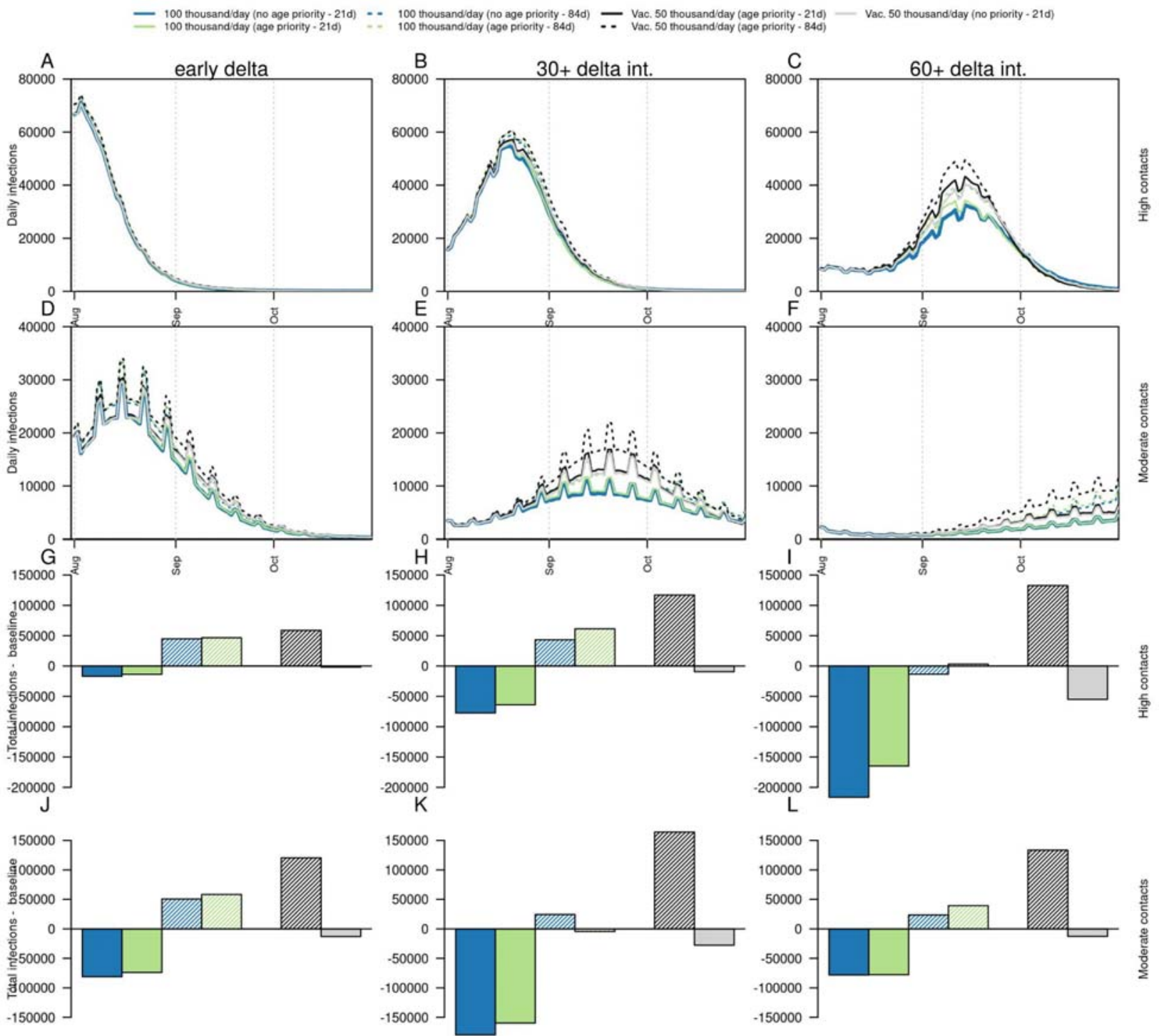

Fig S7. Projections of potential impact on infections of delta variant on a fourth SARS-CoV-2 wave in Bogotá, according to timing of delta introduction, level of social mixing, and vaccination strategies, under an alternative scenario of $\mathrm{VE}$ against infection (100\% of VE against symptoms). Columns show the timing of delta introduction, defined as early (calibrated), 30+ delta (delayed 30 days), and 60+ delta (delayed 60 days). Panels A-C show the number of infections under a scenario of high social mixing, panels D-F show the number of infections under a scenario of moderate social mixing, panels G-I show the difference in the cumulative number of infections between alternative vaccination strategies and the baseline scenario (50 thousand vaccines/day with age prioritization and non-postponed second dose of the Pfizer vaccine ) with high social mixing, 

mixing. Black line shows the baseline scenario of mobility and current vaccination strategy. Dashed lines show the impact of increasing the interval between doses to 84 days for the Pfizer vaccine. Blue colors show the impact of increased vaccination rates (100,000/day) without age priority. Green colors show the impact of increased vaccination rates (100,000/day) with age priority. Gray colors show the impact of baseline vaccination rates without age priority.

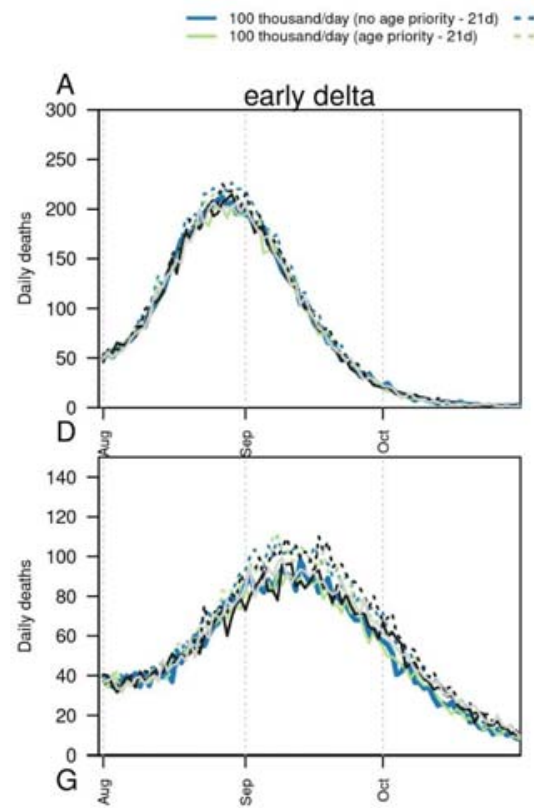

100 thousandiday (no age priority - 84d)
100 thousandiday (age priority - 84 d
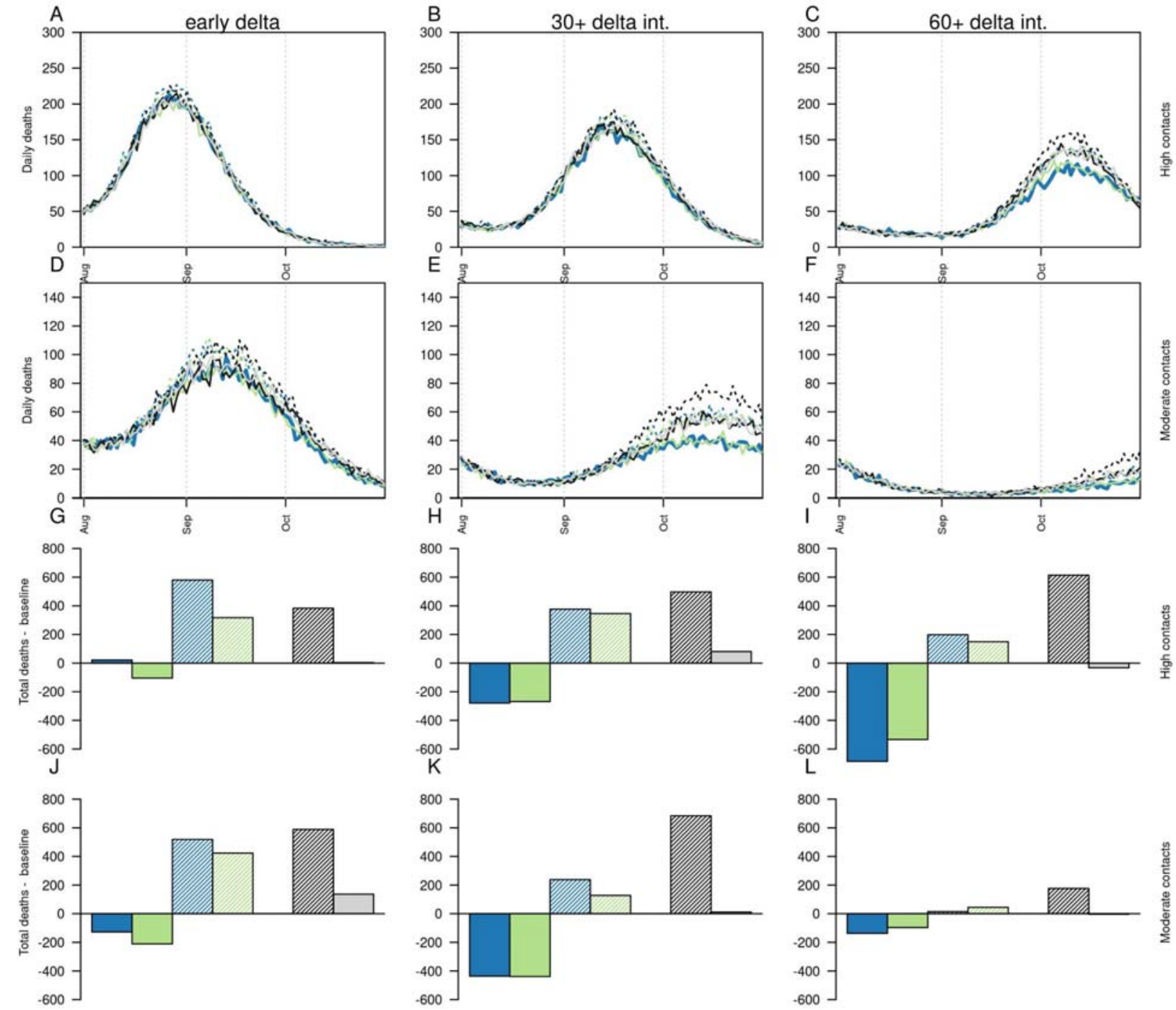

Fig S8. Projections of potential impact on deaths of delta variant on a fourth SARS-CoV-2 wave in Bogotá, according to

infection (100\% of VE against symptomatic disease). Columns show the timing of delta introduction, defined as early (calibrated), 30+ delta (delayed 30 days), and 60+ delta (delayed 60 days). Panels A-C show the daily number of deaths under a scenario of high social mixing, panels D-F show the daily number of deaths under a scenario of moderate social mixing, panels 
(50 thousand vaccines/day with age prioritization and non-postponed second dose of the Pfizer vaccine) with high social mixing, and panels J-L show the difference in the cumulative number of deaths between alternative vaccination strategies and the baseline scenario (50 thousand vaccines/day with age prioritization and non-postponed second dose) with moderate social mixing. Black line shows the baseline scenario of mobility and current vaccination strategy. Dashed lines show the impact of increasing the interval between doses to 84 days for the Pfizer vaccine. Blue colors show the impact of increased vaccination rates $(100,000 /$ day) without age priority. Green colors show the impact of increased vaccination rates (100,000/day) with age priority. Gray colors show the impact of baseline vaccination rates without age priority.

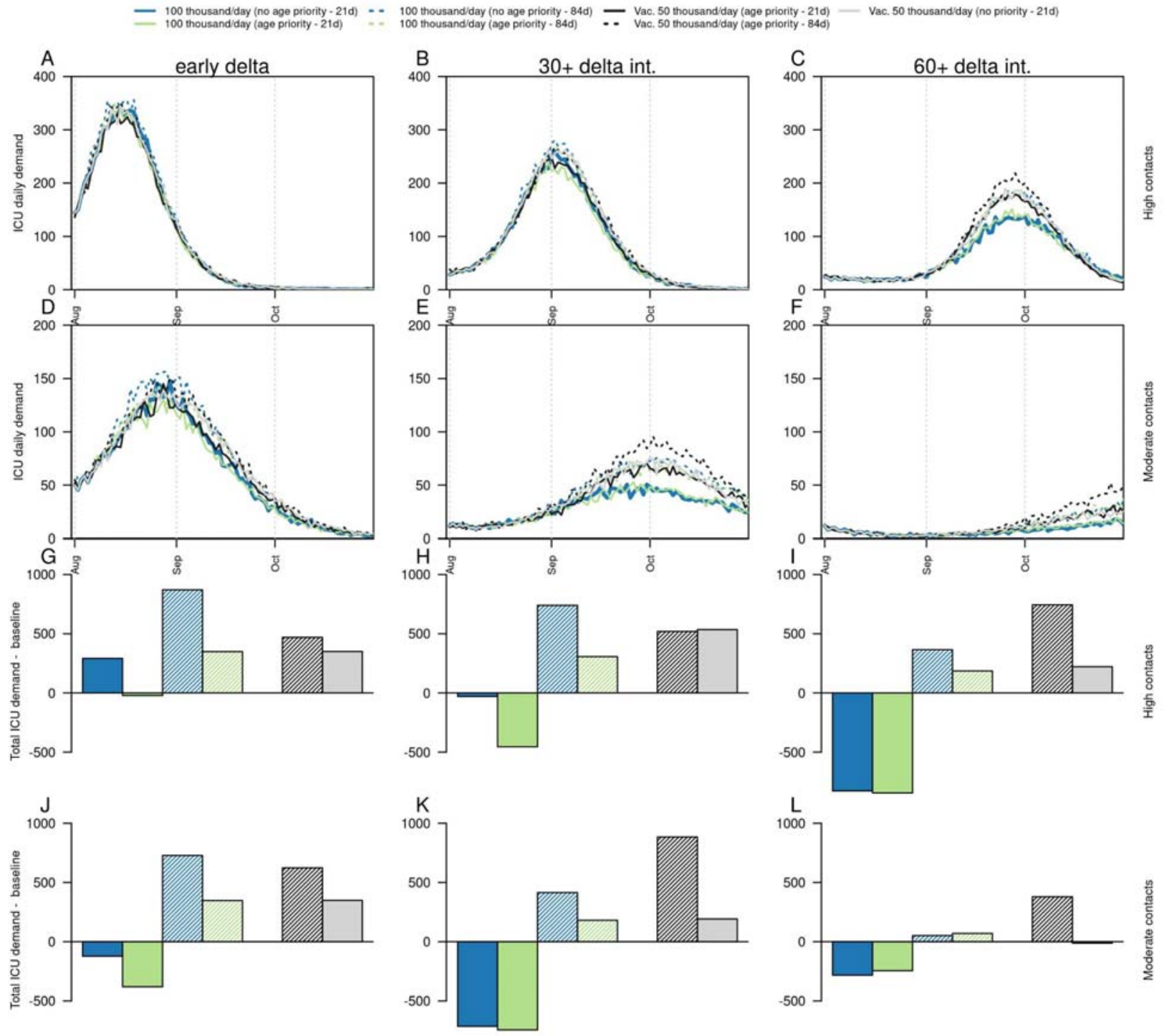

Fig S9. Projections of potential impact on ICU beds demand of delta variant on a fourth SARS-CoV-2 wave in Bogotá, according to timing of delta introduction, level of social mixing, and vaccination strategies, under an alternative scenario of VE against infection (100\% of VE against symptoms). Columns show the timing of delta introduction, defined as early (calibrated), 30+ delta (delayed 30 days), and 60+ delta (delayed 60 days). Panels A-C show the daily number of ICU demand under a scenario of high social mixing, panels D-F show the daily number of ICU demand under a scenario of moderate social 
medRxiv preprint doi: https://doi.org/10.1101/2021.08.06.21261734; this version posted September 7, 2021. The copyright holder for this preprint

(which was not certified by peer review) is the author/funder, who has granted medRxiv a license to display the preprint in perpetuity.

It is made available under a CC-BY 4.0 International license.

537 mixing, panels G-I show the difference in the cumulative number of ICU beds between alternative vaccination strategies and the

538 baseline scenario (50 thousand vaccines/day with age prioritization and non-postponed second dose of the Pfizer vaccine ) with

539 high social mixing, and panels J-L show the difference in the cumulative number of ICU beds between alternative vaccination

540 strategies and the baseline scenario (50 thousand vaccines/day with age prioritization and non-postponed second dose) with

541 moderate social mixing. Black line shows the baseline scenario of mobility and current vaccination strategy. Dashed lines show

542 the impact of increasing the interval between doses to 84 days for the Pfizer vaccine. Blue colors show the impact of increased

543 vaccination rates (100,000/day) without age priority. Green colors show the impact of increased vaccination rates (100,000/day)

544 with age priority. Gray colors show the impact of baseline vaccination rates without age priority.

545

546

547 


\section{References}

549 1. Instituto Nacional de Salud, Colombia. Datos Coronavirus Colombia. [cited 4 Aug 2021].

550 Available: https://www.ins.gov.co/Noticias/Paginas/Coronavirus.aspx

2. Observatorio de Salud de Bogotá, SaluData. Casos confirmados de COVID-19 en Bogotá. [cited 4 Aug 2021]. Available: https://saludata.saludcapital.gov.co/osb/index.php/datos-desalud/enfermedades-trasmisibles/covid19/

3. Ministerio de Salud y Protección Social de Colombia. Vacunación contra COVID-19. [cited 6 Aug 2021]. Available: https://www.minsalud.gov.co/salud/publica/Vacunacion/Paginas/Vacunacion-covid-19.aspx

4. Ritchie H, Ortiz-Ospina E, Beltekian D, Mathieu E, Hasell J, Macdonald B, et al. Coronavirus Pandemic (COVID-19). Our World in Data. 2020 [cited 4 Aug 2021]. Available: https://ourworldindata.org/covid-vaccinations?country=COL

5. Observatorio de Salud de Bogotá, SaluData. COVID-19 Vacunómetro. [cited 4 Aug 2021]. Available: https://saludata.saludcapital.gov.co/osb/index.php/datos-de-salud/enfermedadestrasmisibles/covid-19-vacunometro/

6. Laiton-Donato K, Franco-Muñoz C, Álvarez-Díaz DA, Ruiz-Moreno HA, Usme-Ciro JA, Andrés Prada D, et al. Characterization of the emerging B.1.621 variant of interest of SARS-CoV-2. bioRxiv. medRxiv; 2021. doi:10.1101/2021.05.08.21256619

7. CoVariants. [cited 2 Jul 2021]. Available: http://covariants.org

8. Lopez Bernal J, Andrews N, Gower C, Gallagher E, Simmons R, Thelwall S, et al.

9. Krause PR, Fleming TR, Longini IM, Peto R, Briand S, Heymann DL, et al. SARS-CoV-2

10. España G, Cucunubá ZM, Diaz H, Cavany S, Castañeda N, Rodriguez L. The impact of school reopening on COVID-19 dynamics in Bogotá, Colombia. OSF Preprints. 2021. doi:10.31219/osf.io/ebjx9

11. España G, Cavany S, Oidtman R, Barbera C, Costello A, Lerch A, et al. Impacts of K-12 school reopening on the COVID-19 epidemic in Indiana, USA. Epidemics. 2021. doi:10.1016/j.epidem.2021.100487

12. Moghadas SM, Vilches TN, Zhang K, Nourbakhsh S, Sah P, Fitzpatrick MC, et al. Evaluation of COVID-19 vaccination strategies with a delayed second dose. PLoS Biol. 2021;19: e3001211.

13. Romero-Brufau S, Chopra A, Ryu AJ, Gel E, Raskar R, Kremers W, et al. Public health impact of delaying second dose of BNT162b2 or mRNA-1273 covid-19 vaccine: simulation 
agent based modeling study. BMJ. 2021;373: n1087.

584 585

586

587

588

14. Robertson JFR, Sewell HF. COVID-19 vaccine efficacy data: solid enough to delay second dose? The Lancet. 2021. pp. 2248-2249.

15. Iacobucci G, Mahase E. Covid-19 vaccination: What's the evidence for extending the dosing interval? BMJ. 2021;372: n18.

16. Ledford H. Delaying a COVID vaccine's second dose boosts immune response. Nature. 2021. doi:10.1038/d41586-021-01299-y

17. Voysey M, Costa Clemens SA, Madhi SA, Weckx LY, Folegatti PM, Aley PK, et al. Single-dose administration and the influence of the timing of the booster dose on immunogenicity and efficacy of ChAdOx1 nCoV-19 (AZD1222) vaccine: a pooled analysis of four randomised trials. Lancet. 2021;397: 881-891.

18. Departamento Administrativo Nacional de Estadísticas, DANE. Encuesta Pulso Social. [cited 7 Aug 2021]. Available: https://www.dane.gov.co/index.php/estadisticas-portema/encuesta-pulso-social

19. Pouwels K, Pritchard E, Matthews P, Stoesser, N, al. ED et. Impact of Delta on viral burden and vaccine effectiveness against new SARS-CoV-2 infections in the UK. Available: https://www.ndm.ox.ac.uk/files/coronavirus/covid-19-infectionsurvey/finalfinalcombinedve20210816.pdf

20. Instituto Nacional de Salud, Colombia. Datos Coronavirus Colombia. In: https://www.ins.gov.co/Noticias/paginas/coronavirus.aspx [Internet]. [cited 7 Aug 2021]. Available: https://www.ins.gov.co/Noticias/paginas/coronavirus.aspx

21. Mercado-Reyes M, Malagón-Rojas JN, Zapata S, Rodriguez-Barraquer I, Toloza-Pérez YG, Wiesner M, et al. Seroprevalence of Anti-Sars-Cov-2 Antibodies in Colombia, 2020: A Population-Based Study. SSRN. 2021. Available: https://papers.ssrn.com/abstract=3890833

22. GISAID - Initiative. [cited 2 Aug 2021]. Available: https://www.gisaid.org/

23. Google. COVID-19 Community Mobility Reports. Available: https://www.google.com/covid19/mobility/

24. UNDP. Impacto de las Políticas de Aislamiento a partir del COVID 19. [cited 5 Aug 2021]. Available: https://covid.grandata.com

25. Ministerio de Salud y Protección Social, Colombia. Tablero de vacunación COVID-19 Colombia. [cited 7 Aug 2021]. Available: https://drive.google.com/file/d/1N4Vqqp6q8exuYAZgZ79GT9GazsSCHUK/edit

26. Departamento Administrativo Nacional de Estadística (DANE). Proyecciones de población. [cited 6 Aug 2021]. Available: https://www.dane.gov.co/index.php/estadisticas-portema/demografia-y-poblacion/proyecciones-de-poblacion 
27. IPUMS (Integrated Public Use Microdata Series). [cited 5 Aug 2021]. doi:10.4135/9781452225272.n94

28. Mlcochova P, Kemp S, Dhar MS, Papa G, Meng B, Mishra S, et al. SARS-CoV-2 B.1.617.2 Delta variant emergence, replication and sensitivity to neutralising antibodies. bioRxiv. 2021. p. 2021.05.08.443253. doi:10.1101/2021.05.08.443253

29. CoVariants. [cited 4 Aug 2021]. Available: http://Covariants.org

30. Magpantay FMG, Riolo MA, DE Cellès MD, King AA, Rohani P. EPIDEMIOLOGICAL CONSEQUENCES OF IMPERFECT VACCINES FOR IMMUNIZING INFECTIONS. SIAM J Appl Math. 2014;74: 1810-1830.

31. Han S, Cai J, Yang J, Zhang J, Wu Q, Zheng W, et al. Time-varying optimization of COVID-19 vaccine prioritization in the context of limited vaccination capacity. Nat Commun. 2021;12: 4673.

32. Shapiro J, Dean NE, Madewell ZJ, Yang Y, Halloran ME, Longini I. Efficacy estimates for various COVID-19 vaccines: What we know from the literature and reports. bioRxiv. medRxiv; 2021. doi:10.1101/2021.05.20.21257461

33. Stowe J, Andrews N, Gower G, Gallagher E, Utsi L, Simmons R, et al. Effectiveness of COVID-19 vaccines against hospital admission with the Delta (B.1.617.2) variant. [cited 6 Aug 2021]. Available: https://khub.net/web/phe-national/public-library//document_library/v2WsRK3ZlEig/view_file/479607329?_com_liferay_document_library_ web_portlet_DLPortlet_INSTANCE_v2WsRK3ZIEig_redirect=https $\% 3 \mathrm{~A} \% 2 \mathrm{~F} \% 2 \mathrm{Fkhub} . n \mathrm{e}$ t\%3A443\%2Fweb\%2Fphe-national\%2Fpublic-library\%2F-

\%2Fdocument_library\%2Fv2WsRK3ZIEig\%2Fview\%2F479607266

34. SAGE SPI-M-O. SPI-M-O: Summary of further modelling of easing restrictions - Roadmap Step 2. In:

https://assets.publishing.service.gov.uk/government/uploads/system/uploads/attachment_dat a/file/975909/S1182_SPI-M-

O_Summary_of_modelling_of_easing_roadmap_step_2_restrictions.pdf [Internet]. 3 Jan 2021. Available:

https://assets.publishing.service.gov.uk/government/uploads/system/uploads/attachment_dat a/file/975909/S1182_SPI-M-

O_Summary_of_modelling_of_easing_roadmap_step_2_restrictions.pdf

35. World Health Organization. Interim recommendations for use of the ChAdOx1-S [recombinant] vaccine against COVID-19 (AstraZeneca COVID-19 vaccine AZD1222, SII Covishield, SK Bioscience): interim guidance, first issued 10 February 2021, updated 21 April 2021. World Health Organization; 2021. Report No.: WHO/2019nCoV/vaccines/SAGE_recommendation/AZD1222/2021.2. Available: https://apps.who.int/iris/handle/10665/340920

36. Palacios R, Batista AP, Albuquerque CSN, Patiño EG, Santos J do P, Tilli Reis Pessoa Conde M, et al. Efficacy and Safety of a COVID-19 Inactivated Vaccine in Healthcare 
Professionals in Brazil: The PROFISCOV Study. SSRN. 2021. doi:10.2139/ssrn.3822780

37. Ministerio de Salud, Gobierno de Chile. Efectividad de la vacuna CoronaVac con virus inactivo contra SARS-CoV-2 en Chile. [cited 6 Aug 2021]. Available: https://www.minsal.cl/wp-content/uploads/2021/04/20210416_ESTUDIO-EFECTIVIDADCORONAVAC.pdf

38. BioNTech PA. Pfizer and BioNTech Confirm High Efficacy and No Serious Safety Concerns Through Up to Six Months Following Second Dose in Updated Topline Analysis of Landmark COVID-19 Vaccine Study. [cited 5 Aug 2021]. Available: https://www.pfizer.com/news/press-release/press-release-detail/pfizer-and-biontechconfirm-high-efficacy-and-no-serious

39. Baden LR, El Sahly HM, Essink B, Kotloff K, Frey S, Novak R, et al. Efficacy and Safety of the mRNA-1273 SARS-CoV-2 Vaccine. N Engl J Med. 2021;384: 403-416.

40. Sadoff J, Gray G, Vandebosch A, Cárdenas V, Shukarev G, Grinsztejn B, et al. Safety and Efficacy of Single-Dose Ad26.COV2.S Vaccine against Covid-19. N Engl J Med. 2021;384: 2187-2201.

41. Khoury DS, Cromer D, Reynaldi A, Schlub TE, Wheatley AK, Juno JA, et al. Neutralizing antibody levels are highly predictive of immune protection from symptomatic SARS-CoV-2 infection. Nat Med. 2021;27: 1205-1211.

42. Wall EC, Wu M, Harvey R, Kelly G, Warchal S, Sawyer C, et al. Neutralising antibody activity against SARS-CoV-2 VOCs B.1.617.2 and B.1.351 by BNT162b2 vaccination. Lancet. 2021;397: 2331-2333.

43. SARS-CoV-2 Variants of Concern and Variants Under Investigation in England: Technical briefing 7. Public Health England; 2021.

44. Faria NR, Mellan TA, Whittaker C, Claro IM, Candido D da S, Mishra S, et al. Genomics and epidemiology of the P.1 SARS-CoV-2 lineage in Manaus, Brazil. Science. 2021;372: 815-821. 